\title{
Volatility Modelling of the BRICS Stock Markets
}

\author{
Rosinah M. Mukhodobwane ${ }^{1, *}$, Caston Sigauke ${ }^{2}$, Wilbert Chagwiza ${ }^{1}$, Winston Garira ${ }^{1}$ \\ ${ }^{1}$ Department of Mathematics and Applied Mathematics, University of Venda, South Africa \\ ${ }^{2}$ Department of Statistics, University of Venda, South Africa
}

\begin{abstract}
Volatility modelling is a key factor in equity markets for risk and portfolio management. This paper focuses on the use of a univariate generalized autoregressive conditional heteroscedasticity (GARCH) models for modelling volatility of the BRICS (Brazil, Russia, India, China and South Africa) stock markets. The study extends the literature by conducting the volatility modelling under the assumptions of seven error distributions that include the normal, skewed-normal, Student's $t$, skewed-Student's $t$, generalized error distribution (GED), skewed-GED and the generalized hyperbolic (GHYP) distribution. It was observed that using an $\operatorname{ARMA}(1,1)-\operatorname{GARCH}(1,1)$ model, volatilities of the Brazilian Bovespa and the Russian IMOEX markets can both be well characterized (or described) by a heavy-tailed Student's $t$ distribution, while the Indian NIFTY market's volatility is best characterized by the generalized hyperbolic (GHYP) distribution. Also, the Chinese SHCOMP and South African JALSH markets' volatilities are best described by the skew-GED and skew-Student's $t$ distribution, respectively. The study further observed that the persistence of volatility in the BRICS markets does not follow the same hierarchical pattern under the error distributions, except under the skew-Student's $t$ and GHYP distributions where the pattern is the same. Under these two assumptions, i.e. the skew-Student's $t$ and GHYP, in a descending hierarchical order of magnitudes, volatility with persistence is highest in the Chinese market, followed by the South African market, then the Russian, Indian and Brazilian markets, respectively. However, under each of the five non-Gaussian error distributions, the Chinese market is the most volatile, while the least volatile is the Brazilian market.
\end{abstract}

Keywords Equity markets, Error distributions, GARCH model, Information criteria, Residuals, Risk management, Volatility.

DOI: $10.19139 /$ soic-2310-5070-977

\section{Introduction}

The British economist Jim O'Neill conceptualized the word BRICS as an acronym of five key emerging regional economies of Brazil, Russia, India, China and South Africa. Prior to the introduction of South Africa in 2010, the first four nations were formerly called "BRIC". The term BRIC came into light in a paper of Goldman Sachs [39] where long-term economic growth rates were projected for the four nations till 2050 [29]. The BRICS nations cover $40 \%$ (approximately) of the world's population, create an approximate $20 \%$ of global output [21], and have an estimate of US $\$ 4.7 \mathrm{tn}$ in joint foreign reserves [31]. The BRICS economies' Growth Domestic Product (GDP) amounted to \$13.2tn in 2011, which is fairly over the Eurozone's of \$13.1tn and not far off from the U.S. of \$15.1tn [10].

In 2015, the BRICS proposed plans for economic, investment and trade cooperation until 2020 in view of having a unified mega market with a land-air-sea connection network [38]. Presently, the BRICS Development Bank which is currently known as the "New Development Bank" (NDB), and the Contingent Reserve Arrangement (CRA) are

\footnotetext{
${ }^{*}$ Correspondence to: Rosinah M. Mukhodobwane (Email: rosinah.mukhodobwane @ univen.ac.za). Department of Mathematics, University of Venda, Private Bag X5050, University road, Thohoyandou, Limpopo province, 0950, South Africa.
}

ISSN 2310-5070 (online) ISSN 2311-004X (print)

Copyright (C) 2020 International Academic Press 
actively operating after joint approval by all BRICS nations. In particular, the BRICS states have reinforced their trade and economic relations through consensus approval of bilateral trade and cross-regional agreements [38].

Time series volatility implies a situation where the conditional variance of the return series varies over time. Volatility summarily helps financial market participants to understand (market) risk and describes the size of changes on the market within a certain time period [15]. Volatility modelling in financial markets is very vital for risk management and options trading, hence this study is motivated by the need to model the volatility in the BRICS return series in order to ascertain the level of potential risk associated with each of the markets for investors' decision making. That is, the study will examine the dynamics of market returns volatility in the stock markets of the five BRICS nations. These markets are selected because they, as a team, are progressively and increasingly becoming a propelling force on global economic growth [38] and they are of particular interest to investors and practitioners.

The modelling and analyses were done using the daily closing market data for the five BRICS indices. These data were analysed using the GARCH model, while the conditional mean equation of the GARCH process is modelled using an ARMA (Autoregressive Moving Average) model. Engle [11] was the proponent of the ARCH (autoregressive conditional heteroscedasticity) model, but it was later generalized by Bollerslev [6] as Generalized ARCH (GARCH). The GARCH model can be used to determine the source and magnitude of volatility.

Several empirical research works have been carried out in the past on cross-country equity market's returns and volatility. These, among others, include Kennedy and Sharma [23] for London, New York and Bombay; Grieb and Reyes [17] for Brazil and Mexico. Makhwiting et al. [27] applied ARMA-GARCH type models to model the volatility and financial market risk of the Johannesburg Stock Exchange's (JSE) shares. From the different candidates joint ARMA-GARCH model used, the authors findings from the study revealed that the most accurate volatility forecast is achieved by $\operatorname{ARMA}(0,1)-\operatorname{GARCH}(1,1)$ model. This study will further extend the scope of research done in the literature by modelling volatility of these BRICS markets under the assumption of seven error distributions of a normal, skewed-normal, Student's $t$, skewed-Student's $t$, GED, skewed-GED, and GHYP distribution.

With the BRICS economies on a global spotlight, the dynamic analysis of their markets' volatilities is paramount to international investors, policy makers and all market participants who are interested in portfolio diversifications in their stock markets. Ijumba [20] investigated the levels of interdependence and dynamic linkage among the BRICS countries for weekly data from 2000 to 2012. The study employed a Vector Autoregressive (VAR), univariate $\operatorname{GARCH}(1,1)$ and multivariate GARCH models. The results from VAR showed that there is unidirectional linear dependence of Indian and Chinese stock markets on Brazilian market. On the other hand, the univariate $\operatorname{GARCH}(1,1)$ model revealed the presence of volatility persistence in all the BRICS markets' stock returns. China was found to be the most volatile, followed by Russia, and South Africa was the least volatile. Multivariate GARCH also showed that there is volatility persistence among BRICS stock markets.

Zhang et al. [40] used the causality-in-variance test developed by Herwartz and Hafner [19] to study volatility transmissions (spill-overs) between the bond and equity markets of the BRICS and G7 nations from December 1988 to December 2012. The findings showed, at 1\% significance level, a unidirectional spill-overs from the bond to the stock markets in the UK, Germany and U.S. For South Africa, France and Brazil, the findings observed a bidirectional volatility spill-overs between the bond and equity markets, but no definite directional conclusion was made for Canada, Italy, Japan, China and India. Romero and Kasibhatla [33] studied the volatility dynamics and out-of-sample forecasts of each of the four BRIC's (markets') returns using GARCH models. The study was conducted under the assumptions of three distributions of a normal, Student's $t$, and GED (generalized error distribution) from January 2000 to December 2010. Their findings showed statistically significant indication of asymmetric impact of bad and good news in each of the markets. Furthermore, the Student's $t$ error distribution was the best to describe the Brazilian, Russian and Indian markets, while the Chinese market was best characterized by the GED.

Javed et al. [22] used the Threshold ARCH (TARCH) and GARCH models to analyse the volatility of the BRICS stocks data from 2003 to 2018 and observed that the TARCH model outperformed the GARCH approach. The two models were further used to model the returns of the bloc, where the GARCH model performed better than the TARCH model. Adua et al. [1] examined the distribution of the BRICS stock markets from data spanning 1995 
to 2014 and observed that volatility clustering prevails in the markets. The authors also showed that the decay of the volatility clustering was exponential for all except Brazil. Salisu and Gupta [34] analysed the response effect of the BRICS stock markets volatility on their oil shocks using the Generalised Autoregressive Conditional Heteroskedasticity variant of Mixed Data Sampling (GARCH-MIDAS) model. The authors' findings revealed heterogeneous response from the volatility of the BRICS stock markets to the oil's negative and positive shocks.

With some exceptions (e.g. [20]; [40]; [22]; [1]), it can be observed from the literature that little research has been carried out on modelling the volatility of the collective BRICS stock returns series. It is even more important to emphasize the fact that with this little research work done, none has modelled the markets with the collective seven error distributions we have used in this study. Hence, to the best of the authors' knowledge, this study is possibly the first attempt to formally model and analyse the BRICS stock markets' volatility with potential contribution to the literature using these seven error distributions together.

This paper focuses on modelling volatility of the BRICS stock returns using GARCH models under the assumption of the stated seven error distributions. The models and error distributions are discussed in Section 2. Empirical results are presented and discussed in Section 3, while Section 4 draws conclusions.

\section{Models}

\subsection{ARCH model}

The ARCH model was first proposed by Engle [11] for modelling the changing variance of a time series due to the non-constant conditional variance of financial asset's return series $\left(r_{t}\right)$, given past returns. For the conditional variance, the ARCH (1) model is specified as:

$$
\sigma_{t}^{2}=\omega+\alpha \varepsilon_{t-1}^{2},
$$

where $\alpha$ and $\omega$ are unknown parameters and $\varepsilon_{t-1}^{2}$ is a lagged innovation term. Also $\omega \geq 0$ and $\alpha \geq 0$ (positive conditions) are necessary to ensure that $\sigma_{t}^{2} \geq 0$. Another necessary condition to ensure stationarity is that $\alpha<1$.

This model is generalized to an $\mathrm{ARCH}(v)$ model as:

$$
\sigma_{t}^{2}=\omega+\sum_{j=1}^{v} \alpha_{j} \varepsilon_{t-j}^{2},
$$

where $\alpha_{j}$ are parameters with $j=1, \ldots, v$.

\subsection{Parsimonious parametrization of the GARCH model}

Engle [11] introduced a volatility process with time varying conditional variance: the ARCH process. However in practice, empirical evidence shows that a large lag order or high $\mathrm{ARCH}$ order has to be selected for the ARCH modelling. This high ARCH order implies the estimation of many parameters, and that usually leads to tedious calculations. To reduce this computational burden, Bollerslev [6] extended the ARCH model of Engle by including past conditional variances. This was actualized by proposing the generalised ARCH model (GARCH) as a natural solution to the challenge faced by the high ARCH orders. The GARCH model is based on an infinite ARCH specification, and it intensely reduced the number of estimated parameters from an infinite number to just a few.

Thus, a GARCH specification often leads to a more parsimonious representation of the conditional variance process and provides added flexibility over the linear ARCH model when parametrizing the conditional variance. It gives parsimonious models that are easy to estimate and, even in its simplest form, has proven remarkably successful in forecasting conditional variances [12].

\subsection{The GARCH model}

Modelling of the magnitudes of the BRICS markets returns volatility will be done via the use of GARCH model developed by Bollerslev [6]. The conditional variance of the GARCH model is stated as a linear function of its own 
lags, and the model is usually specified by its conditional variance and conditional mean equations. The simplest model specification is $\operatorname{GARCH}(1,1)$ model with the mean equation defined as:

$$
\text { Mean equation : } r_{t}=\mu+\varepsilon_{t},
$$

where $r_{t}$ denotes the return series, $\varepsilon_{t}$ is the part of the time series return that is unpredictable and it is known as the residuals or innovations, $\mu$ denotes the mean function usually expressed as an ARMA process, i.e.,

$$
\mu_{t}=\sum_{i=1}^{p} \phi_{i} r_{t-i}+\sum_{i=1}^{q} \theta_{i} \varepsilon_{t-i} .
$$

where $\theta_{i}$ and $\phi_{i}$ are parameters with $i=1, \ldots, q$ and $i=1, \ldots, p$ respectively. In this study, this volatile residual $\left(\varepsilon_{t}\right)$ of the return will be modelled assuming the following distributions: normal, Student's $t$, generalized error distribution (with their skew variants) and the generalized hyperbolic (GHYP) distribution.

The variance equation of the $\operatorname{GARCH}(k, v)$ can be stated as

$$
\begin{gathered}
\varepsilon_{t}=z_{t} \sigma_{t} \\
z_{t} \sim N(0,1) \\
\sigma_{t}^{2}=\omega+\sum_{j=1}^{v} \alpha_{j} \varepsilon_{t-j}^{2}+\sum_{i=1}^{k} \beta_{i} \sigma_{t-i}^{2},
\end{gathered}
$$

i.e. the conditional variance $\sigma_{t}^{2}$ of the $\operatorname{GARCH}(k, v)$ model is a linear function of the past conditional variances and past squared innovation. The $\omega$ represents the intercept and $z_{t}$ denotes the standardized residual returns. The residuals are random variables with variance 1 and mean 0 [37] and they are known to be independent and identically distributed, i.i.d., [28].

\subsection{Conditional distributions}

This section describes the seven main univariate error distributions used in this study for modelling the markets' volatilities, and they include the normal, skewed-normal, Student's $t$, skewed-Student's $t$, GED, skewed-GED and the GHYP distribution.

2.4.1. The normal distribution The normal distribution is characterized entirely by its mean and variance (which are its first two moments). It is a symmetric and uni-modal (i.e., singe-peaked) distribution having zero excess kurtosis and zero skewness. A random variable $X$ can be described as normally distributed with mean $\mu$ and variance $\sigma^{2}$. The density is stated as [16]:

$$
f(x)=\frac{e^{\frac{-\frac{1}{2}(x-\mu)^{2}}{\sigma^{2}}}}{\sigma \sqrt{2 \pi}} .
$$

When the residuals $\varepsilon$ are standardized by $\sigma^{2}$ (following a mean filtration process), it produces the standard normal density expressed as

$$
f\left(\frac{x-\mu}{\sigma}\right)=\frac{1}{\sigma} f(z)=\frac{1}{\sigma}\left(\frac{e^{-\frac{1}{2} z^{2}}}{\sqrt{2 \pi}}\right)
$$

2.4.2. The skewed-normal distribution The skewed-normal $(S N)$ is a parametric class of probability distributions with a shape parameter $\xi$ that regulates the skewness. Hence, it is an extension of the normal distribution that allows for a continuous variation from normality to non-normality [2].

Let $\phi(\cdot)$ and $\Phi(\cdot)$ be the standard normal density function and (its) distribution function respectively for a random variable $X$ with $\xi$ as the shape parameter $[9,2]$. The probability density function (pdf) of the skewed-normal distribution is then given as (see [3]) 


$$
f(x)=2 \phi(x) \Phi(\xi x), \quad(-\infty<x<\infty), \xi \in \mathbb{R} .
$$

The density function in equation (8) can be stated as [2]

$$
f(x)=2 \frac{1}{\sqrt{2 \pi}} \exp \left(-x^{2} / 2\right) \int_{-\infty}^{\xi x} \frac{1}{\sqrt{2 \pi}} \exp \left(-t^{2} / 2\right) d t
$$

where $X \sim S N(0,1, \xi)$ for $-\infty<x<\infty$ and any given $\xi \in \mathbb{R}$. When $\xi=0$, the $S N$ distribution reduces to the normal distribution, but it becomes the half-normal distribution if $\xi \rightarrow \pm \infty$. The skewness of the distribution increases as $\xi$ increases (in absolute value). The square of a random variable that follows an $S N$ distribution is a Chi-square variable with one degree of freedom $\left(X^{2} \sim \chi_{1}^{2}\right)$ irrespective of the value of $\xi$ [3]. For practical numerical work, the scale and location parameters can be incorporated by transforming linearly as $Y=\mu+\sigma X$, where $\mu$ and $\sigma$ are the location and scale parameters respectively. This then follows the skewed-normal distribution $Y \sim S N\left(\mu, \sigma^{2}, \xi\right)$, with $\sigma>0$ [9].

An alternative representation of the skewed-normal distribution that is useful for financial (return) modelling was presented by Pourahmadi [32]. In this way, the expression $Y \sim S N\left(\mu, \sigma^{2}, \xi\right)$ is written as a weighted average of a half-normal and a standard normal variable:

$$
Y=\mu+\sigma X=\mu+\sigma\left(\delta\left|Z_{1}\right|+\sqrt{1-\delta^{2}} Z_{2}\right),
$$

with $\delta=\xi / \sqrt{1+\xi^{2}} \in[-1,1]$. The $Z_{1}$ and $Z_{2}$ are independent $N(0,1)$ random variables. The $Y$ becomes $N\left(\mu, \sigma^{2}\right)$ if $\delta=0$. If equation (10) is interpreted in the language of financial economics, the return $Y$ is driven (with the inclusion of the location parameter $\mu$ ) by a Gaussian element $Z_{2}$ modulated by $\sigma \sqrt{1-\delta^{2}}$ and a halfGaussian element $\left|Z_{1}\right|$ modulated by $\sigma \delta$ [9]. The skewness of the distribution becomes more pronounced to the left (right), the closer the value of $\delta$ is to $-1(+1)$. The impact of $\delta$ can then be highlighted by the mean, variance, skewness and kurtosis of $Y$ as follows:

$$
\begin{aligned}
\mathrm{E}(Y) & =\mu+\sigma \sqrt{2 / \pi} \delta \\
\operatorname{Var}(Y) & =\sigma^{2}\left(1-2 \delta^{2} / \pi\right) \\
\text { Skewness }(Y) & =(4-\pi) / 2\left(\delta(2 / \pi)^{1 / 2}\right)^{3} /\left(1-2 \delta^{2} / \pi\right)^{3 / 2}, \\
\text { Excess Kurtosis }(Y) & =2(\pi-3)\left(\delta(2 / \pi)^{1 / 2}\right)^{4} /\left(1-2 \delta^{2} / \pi\right)^{2} .
\end{aligned}
$$

There is a quadratic link for the variance, whereas the mean is a linear increasing function in the skewness parameter $\delta$. Unlike the normal distribution, the values of the skewed-normal distribution ranges from -1 to 1 and can therefore be calibrated to skewed data. However, the range of possible skewness values is still comparatively limited [9].

2.4.3. The Student's $t$ distribution Like the normal distribution, the Student's $t$ distribution is also uni-modal, symmetric and bell-shaped, but with thicker (or heavier) tails than the normal distribution. As an alternative to the normal distribution, the Student's $t$ distribution can be used to fit the standardized innovations (residuals). It is wholly described by a shape parameter $\xi$, but its 3-parameter representation are used for standardization as follows:

$$
f(x)=\frac{\Gamma\left(\frac{\xi+1}{2}\right)}{\sqrt{\sigma \xi \pi} \Gamma\left(\frac{\xi}{2}\right)}\left(1+\frac{(x-\mu)^{2}}{\sigma \xi}\right)^{-\left(\frac{\xi+1}{2}\right)},
$$

where $\Gamma$ is the Gamma function, while $\xi, \mu$, and $\sigma$ are the shape, location and scale parameters respectively. The mean (and mode) of the $t$ distribution signifies the location parameter $\mu$ while the variance is stated as [16]

$$
\operatorname{Var}(X)=\frac{\sigma \xi}{(\xi-2)} .
$$


It is required that $\operatorname{Var}(X)=1$ for standardization purposes, hence

$$
\sigma=\frac{(\xi-2)}{\xi}\left(\text { from } \frac{\sigma \xi}{(\xi-2)}=1\right)
$$

With $\frac{(\xi-2)}{\xi}$ substituted into equation (15), the standardized Student's $t$ distribution gives

$$
f\left(\frac{x-\mu}{\sigma}\right)=\frac{1}{\sigma} f(z)=\frac{1}{\sigma} \frac{\Gamma\left(\frac{\xi+1}{2}\right)}{\sqrt{(\xi-2) \pi} \Gamma\left(\frac{\xi}{2}\right)}\left(1+\frac{(z)^{2}}{(\xi-2)}\right)^{-\left(\frac{\xi+1}{2}\right)} .
$$

The Student's $t$ distribution has excess kurtosis equal to $6 /(\xi-4)$ for $\xi>4$ and zero skewness.

2.4.4. The skewed-Student's $t$ distribution The skewed version of the Student's $t$ distribution simply termed the "skewed-Student's $t$ " distribution was introduced by Branco and Dey [7], and further developed by Azzalini and Capitanio [4]. This distribution allows regulating both kurtosis and skewness, and that is why it is particularly valuable for modelling capital market data [9]. The standardized Student's $t$ skewed distribution can be stated as

$$
X=\frac{Z}{\sqrt{M / v}}, M \sim \chi^{2}(v)
$$

where $Z$ represents an independent $S N(0,1, \xi)$; but if $N(0,1)$ is used instead, it would yield the Student's $t$ [9]. The parameter $v$ denotes the degrees of freedom.

The random variable $Y$ has a skew- $t$ distribution, i.e. $Y \sim S T\left(\mu, \sigma^{2}, \xi, v\right)$, with parameters $\left(\mu, \sigma^{2}, \xi, v\right)$ following linear transformation from $X$, such that $Y=\mu+\sigma X$. The mean and variance of the distribution can be calculated as follows (more complex presentation of the kurtosis and skewness can be seen in Azzalini and Capitanio [4]

$$
\begin{gathered}
\mathrm{E}(Y)=\mu+\sigma w \delta \\
\operatorname{Var}(Y)=\sigma^{2}\left(\frac{v}{v-2}-w \delta^{2}\right),
\end{gathered}
$$

where $w=\sqrt{\frac{v}{\pi}} \frac{\Gamma\left(\frac{1}{2}(v-1)\right)}{\Gamma\left(\frac{1}{2} v\right)}$, and $\delta$ is a skewness parameter. The variance is a quadratic function on $\delta$, while the mean is a linear increasing function in $\delta$. When the skewed-Student's $t$ distribution is compared with the skew normal distribution, the former is known to take more extreme values for both skewness and kurtosis [9].

2.4.5. The generalized error distribution The generalized error distribution (GED) is symmetric with a 3parameter distribution that belongs to the family of exponential distributions with conditional density stated as

$$
f(x)=\frac{\xi e^{-\frac{1}{2}}\left|\frac{x-\mu}{\sigma}\right|^{\xi}}{2^{1+\xi^{-1}} \sigma \Gamma\left(\xi^{-1}\right)},
$$

where $\mu, \xi$, and $\sigma$ are the location, shape and scale parameters respectively. The GED is also a uni-modal distribution where the location parameter $\mu$ is the mean of the distribution. The kurtosis, Kur and variance, Var are stated as:

$$
\begin{gathered}
\operatorname{Kur}(x)=\frac{\Gamma\left(5 \xi^{-1}\right) \Gamma\left(\xi^{-1}\right)}{\Gamma\left(3 \xi^{-1}\right) \Gamma\left(3 \xi^{-1}\right)} \\
\operatorname{Var}(X)=\sigma^{2} 2^{\frac{2}{\xi}} \frac{\Gamma\left(3 \xi^{-1}\right)}{\Gamma\left(\xi^{-1}\right)}
\end{gathered}
$$


The density becomes flatter and flatter as $\xi$ decreases and it approaches the uniform distribution as the limit $\xi \rightarrow \infty$. When $\xi=1$ and $\xi=2$, the distribution becomes the Laplace and the normal respectively. A unit standard deviation in equation (25) can be obtained by rescaling the density during standardization

$$
\begin{gathered}
\operatorname{Var}(X)=\sigma^{2} 2^{\frac{2}{\xi}} \frac{\Gamma\left(3 \xi^{-1}\right)}{\Gamma\left(\xi^{-1}\right)}=1 \\
\therefore \sigma=\sqrt{2^{-\frac{2}{\xi}} \frac{\Gamma\left(\xi^{-1}\right)}{\Gamma\left(3 \xi^{-1}\right)}}
\end{gathered}
$$

When this is substituted into the scaled density of $z$, it becomes

$$
f\left(\frac{x-\mu}{\sigma}\right)=\frac{1}{\sigma} f(z)=\frac{1}{\sigma} \frac{\xi e^{-\frac{1}{2}\left|\sqrt{2^{-\frac{2}{\xi}} \frac{\Gamma\left(\xi^{-1}\right)}{\Gamma\left(3 \xi^{-1}\right)}} z\right|^{\xi}}}{\sqrt{2^{-\frac{2}{\xi}} \frac{\Gamma\left(\xi^{-1}\right)}{\Gamma\left(3 \xi^{-1}\right)}} 2^{1+\xi^{-1}} \Gamma\left(\xi^{-1}\right)}
$$

2.4.6. The skewed-GED distribution The skewed variant of the generalized error distribution (GED) is called the "skewed-GED (SGED)" distribution. The standardized SGED distribution for a random variable $X$ has a density function expressed as [24]

$$
f\left(x_{t} \mid \xi, \delta\right)=C \cdot \exp \left(-\frac{\left|x_{t}-\eta\right|^{\xi}}{\left[1-\operatorname{sign}\left(x_{t}-\eta\right) \delta\right]^{\xi} \theta^{\xi}}\right),
$$

where $C=\frac{\xi}{2 \theta \cdot \Gamma\left(\frac{1}{\xi}\right)}, \theta=\Gamma\left(\frac{1}{\xi}\right)^{1 / 2} \Gamma\left(\frac{3}{\xi}\right)^{-1 / 2} S(\delta)^{-1}, \eta=2 \delta \cdot A \cdot S(\delta)^{-1}$,

$S(\delta)=\sqrt{1+3 \delta^{2}-4 A^{2} \delta^{2}}$ and $A=\Gamma\left(\frac{2}{\xi}\right) \Gamma\left(\frac{1}{\xi}\right)^{-1 / 2} \Gamma\left(\frac{3}{\xi}\right)^{-1 / 2}$.

The fat-tails and height of the density function are directed by the shape parameter $\xi$ with constraint $\xi>0$, whereas $\delta$ denotes the density's skewness parameter with $-1<\delta<1$. Sign represents the sign function. The SGED distribution takes the form of the standard normal distribution when $\xi=2$ and $\delta=0$. The density function skews to the left (right) with negative (positive) skewness [24].

2.4.7. The generalised hyperbolic distribution The generalised hyperbolic (GHYP) distribution is a normal mixture of variance-mean in which the generalized inverse Gaussian (GIG) distribution is the mixing distribution. It is a continuous probability distribution introduced by Ole Barndorff-Nielsen [5], with the pdf (probability density function) given based on the second kind of modified Bessel function represented by $K_{\lambda}$ [30]. Furthermore, it has semi-heavy tails property that makes it relevant and regularly used in risk management and modelling of financial markets data.

Standardization and estimation of the density requires estimating two invariant parameters, i.e. the location and scale parameters (denoted by $v, \aleph$ ), that denote the shape and skewness combined. Following this is a series of transformation stages to scale and translate the 2 parameters $(v, \aleph)$ into the parametrization of $(\varsigma, \vartheta, \hbar, \imath)$ which generates standard formulae for the likelihood function [16]. For details on the proof of the standardized generalized hyperbolic distribution, see Ghalanos [16].

\subsection{Model selection measures}

Representative statistical models are usually built by researchers to test hypotheses and theories, and then ascertain how well each of the models fit collected data. To determine the theory that best describes the observed data, the candidate models are compared using an objective method. The model that is considered the best by the stipulated method is chosen as the best model, and it favourably indicates that the theory can be represented by the model [8]. Some of the model selection methods include the likelihood ratio tests (LRT), coefficient of determination $\left(R^{2}\right)$, adjusted coefficient of determination $\left(R^{2}\right.$ adj), generalized cross-validation (GCV), the information criteria, among others. 
Common information criteria as defined in equations (28) to (31) include the AIC (Akaike information criterion), BIC (Bayesian information criterion), HQIC (Hannan-Quinn information criterion) and SIC (Shibata information criterion) (see [16]). An information criterion is a function of the value of the log-likelihood (the goodness of fit component) and the number of the model's parameters (the model complexity component). Selection of models using information criteria, underpinned by the information-theoretic framework are more flexible than methods grounded in null hypothesis testing ([18]).

As an advantage, information criteria do not necessitate contending models to relate with each other in any particular way, and the contending (candidate) models do not need to be nested. More so, the use of information criteria can accommodate simultaneous comparison of any number of models, i.e. models comparison is not limited to two at a time, nor is it compulsory to test models incrementally (like Model 1 versus Model 2, Model 2 versus Model 3, etc.). In conclusion, for the fact that information criteria are not based on the framework of null hypothesis testing, designation of any model as a null model is not needed for comparison purposes [8]. Based on these, the goodness of fit of the seven error distributions under the GARCH models will be assessed by these information criteria. In general, the smaller (bigger) the information criterion (the log-likelihood), the better the model's fit.

$$
\begin{gathered}
\mathrm{AIC}=\frac{-2 l}{n}+\frac{2 p}{n}, \\
\mathrm{BIC}=\frac{-2 l}{n}+\frac{p \log _{e}(n)}{n}, \\
\mathrm{HQIC}=\frac{-2 l}{n}+\frac{2 p \log _{e}\left(\log _{e}(n)\right)}{n}, \\
\mathrm{SIC}=\frac{-2 l}{n}+\log _{e}\left(\frac{n+2 p}{n}\right),
\end{gathered}
$$

where $n$ denotes the sample size, $l$ is the log-likelihood of the maximum likelihood of unknown parameter vector $L(\Theta), \log _{e}$ represents the natural logarithm, and $p$ denotes the number of estimated parameters [25].

\section{Results and discussions}

\subsection{Data description}

The raw price data used for this study include the daily closing equity indices of the Brazilian, Russian, Indian, Chinese and South African stock markets. The data were obtained from Thomson Reuters Datastream and are for the period $5^{\text {th }}$ January 2010 to $6^{\text {th }}$ August 2018 with 2126 observations. That is, the data for each of the BRICS indices are recorded for 260 days per year, which is 5 trading days in a week.

The BRICS markets' indices are the IBOV (or Bovespa) index of Brazil Sau Paulo stock exchange, the IMOEX (Moscow Exchange) index of Russia, the Indian NIFTY (or NIFTY 50) index is the national stock exchange of India. Next is the SHCOMP (i.e. the Shanghai Stock Exchange Composite) index of China, and the JALSH (JSE Africa All Share) index of South Africa. Modelling of the volatility of the BRICS markets' returns under each of the selected error distributions and the selection of best fitting model (error distribution) to describe each market will be done using the R package "rugarch" developed by Ghalanos [16].

\subsection{Missing values}

For the period under study, it was observed that six daily closing price values were missing in the South African JALSH index on $24^{\text {th }}$ September 2010, $9^{\text {th }}$ August 2010, $16^{\text {th }}$ June 2010, $27^{\text {th }}$ April 2010, $22^{\text {nd }}$ March 2010 and $27^{t h}$ December 2011. Another missing datum was observed in the Russian IMOEX index for $20^{\text {th }}$ February 2016. Since these were single day each, adjustment was made by using the average value of the day prior to and after each missing day as the values of the closing price (see [26]). 

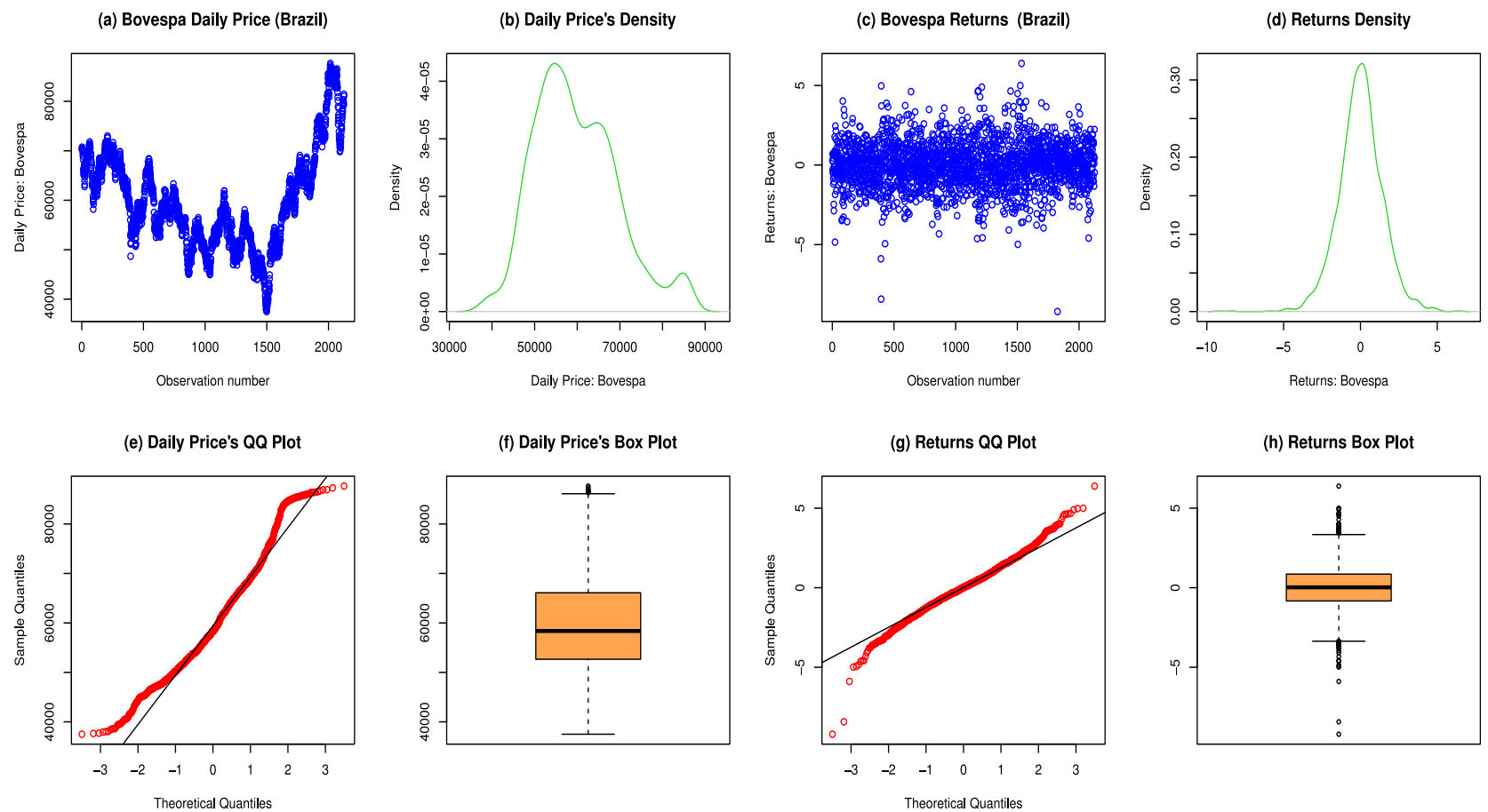

Figure 1. Brazil: EDA of price (panels a, b, e, f) and return (panels c, d, g, h).
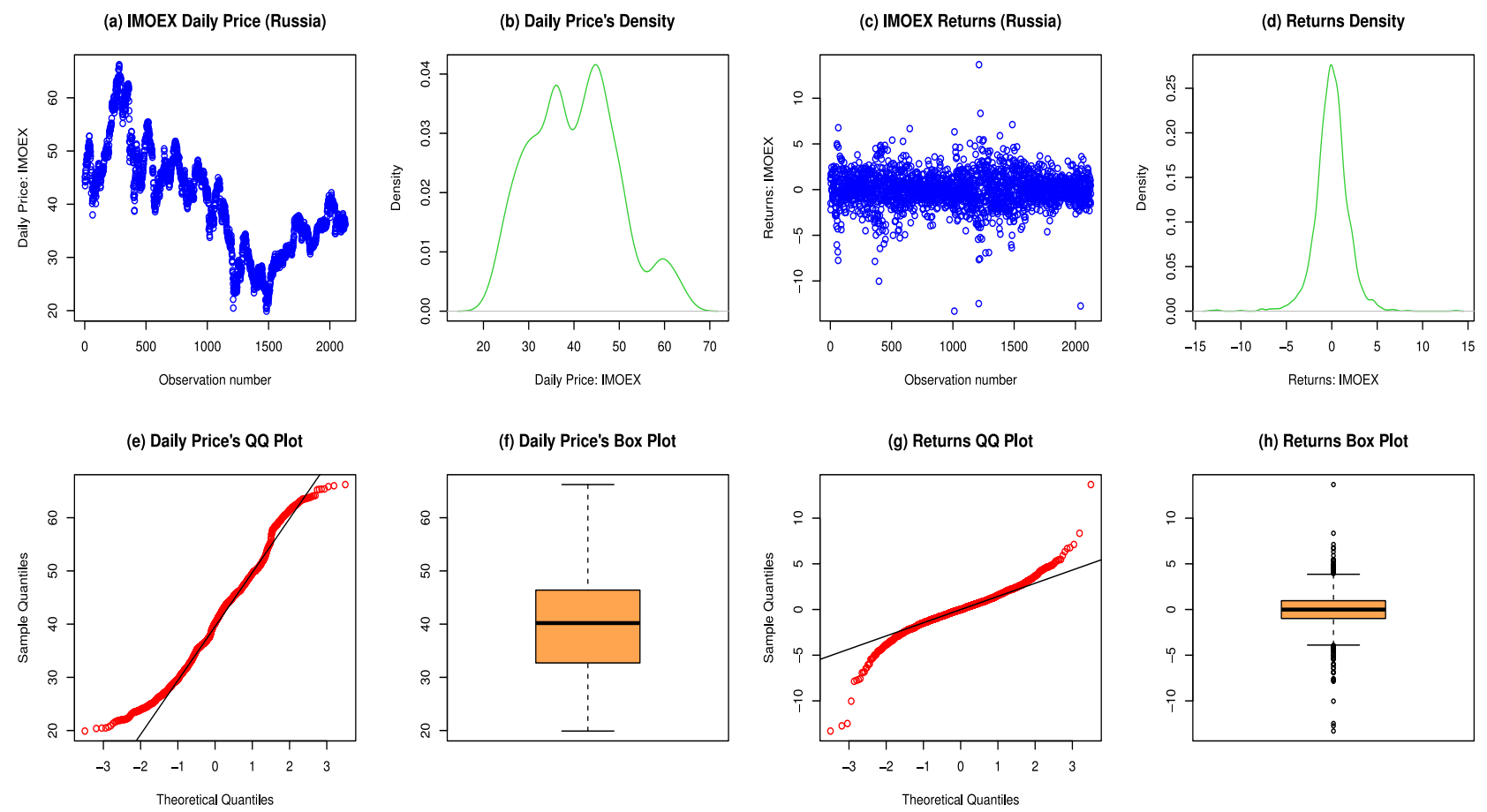

Figure 2. Russia: EDA of price (panels a, b, e, f) and return (panels c, d, g, h). 


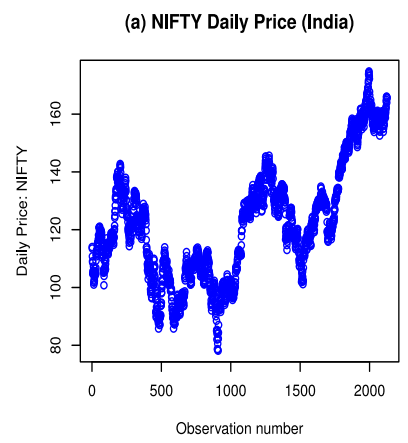

(e) Daily Price's QQ Plot

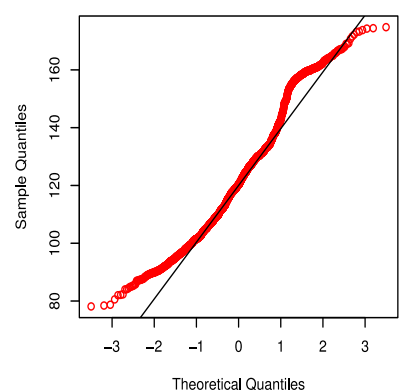

(b) Daily Price's Density

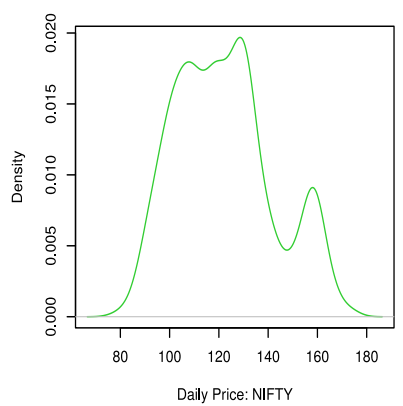

(f) Daily Price's Box Plot

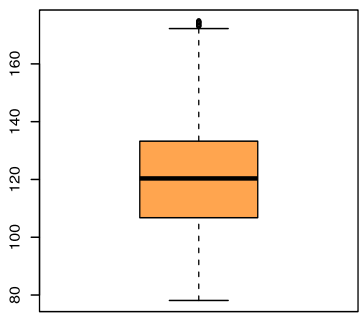

(c) NIFTY Returns (India)

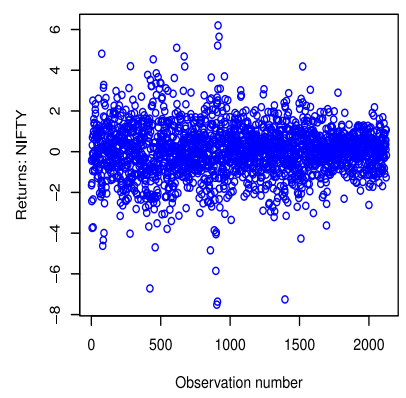

(g) Returns QQ Plot

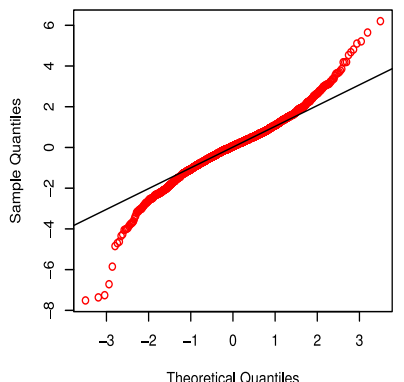

(d) Returns Density

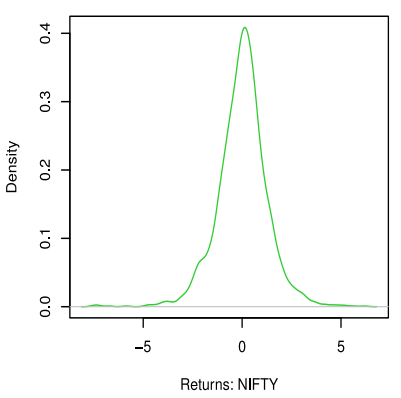

(h) Returns Box Plot

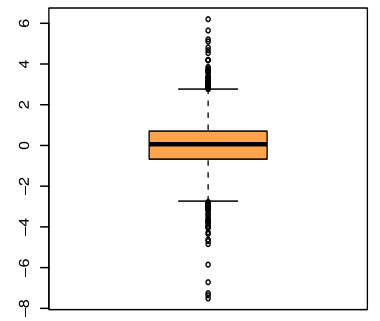

Figure 3. India: EDA of price (panels a, b, e, f) and return (panels c, d, g, h).
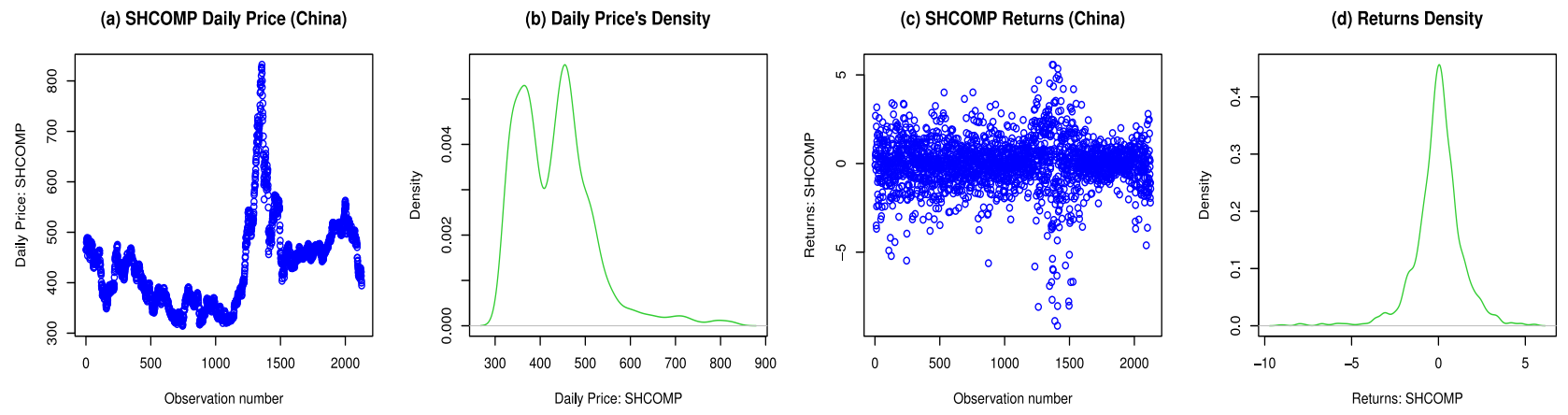

(e) Daily Price's QQ Plot

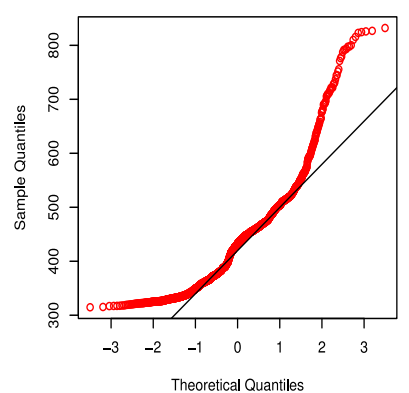

(f) Daily Price's Box Plot

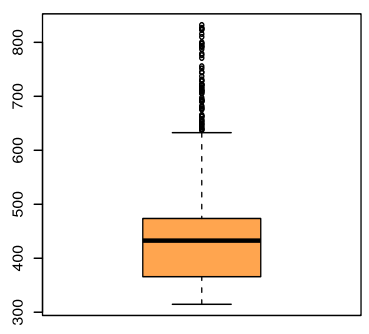

(g) Returns QQ Plot

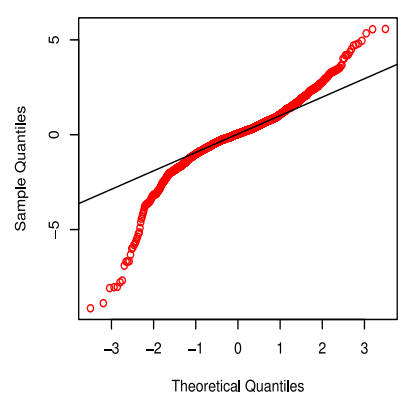

(h) Returns Box Plot

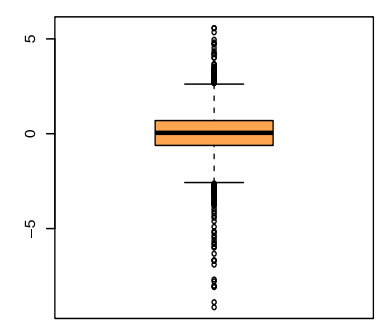

Figure 4. China: EDA of price (panels a, b, e, f) and return (panels c, d, g, h). 

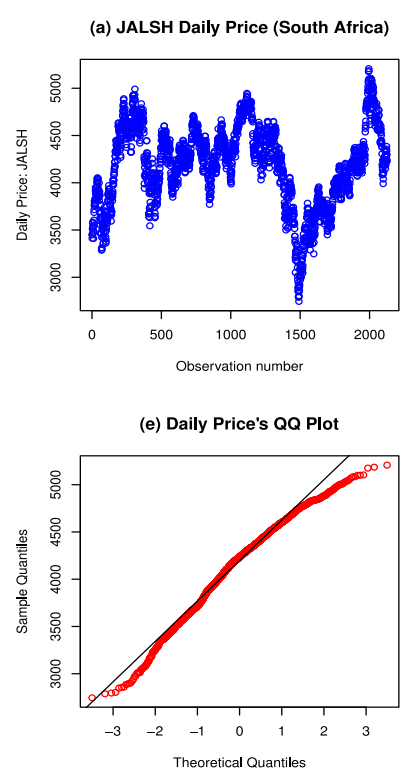

(b) Daily Price's Density

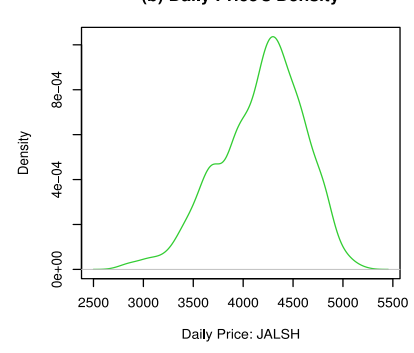

(f) Daily Price's Box Plot

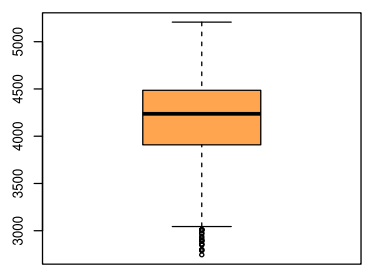

(c) JALSH Returns (South Africa)

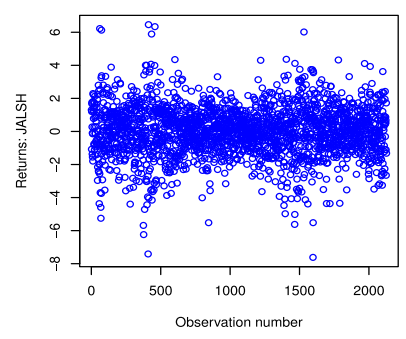

(g) Returns QQ Plot

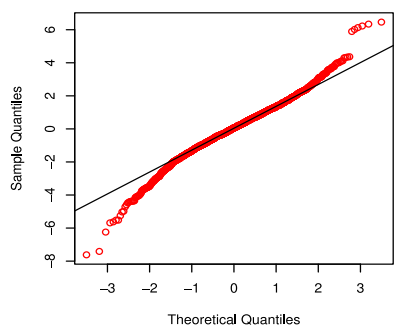

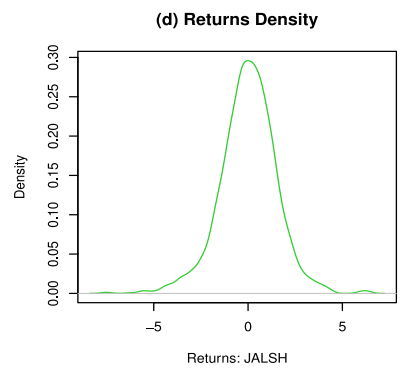

(h) Returns Box Plot

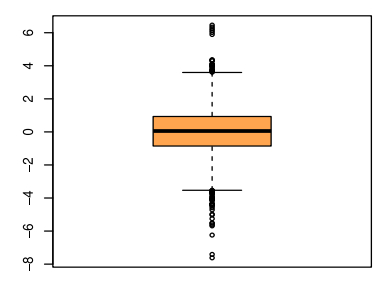

Figure 5. South Africa: EDA of price (panels a, b, e, f) and return (panels c, d, g, h).

The daily closing prices of financial time series like that of the stock market usually exhibit non-stationarity, and empirical studies on such series have shown that approximation to stationarity can be obtained via log-daily returns. By this, logarithms of ratios of successive realizations are taken, and this can generate reasonable transformation to stationarity (from price to return). For convenience of presentation, the generated return series is further re-scaled by multiplying by 100 as follows

$$
r_{t}=\ln \left(\frac{P_{t}}{P_{t-1}}\right) \times 100,
$$

where $t$ is the time period in days, $P_{t}$ signifies the closing stock price index at time $t$, and previous day's closing market price index is $P_{t-1}$. The natural logarithm is denoted by $\ln$, while $r_{t}$ represents the current returns.

\subsection{Exploratory data analysis}

The first requirement in the analysis of any statistical dataset is the exploratory data analysis (EDA) which gives first hand examination of the content of the dataset with regards to detecting outliers and anomalies in the data. Exploratory analysis helps to determine whether the data satisfy basic distributional assumptions and it can suggest useful normalizing transformation.

Figures 1, 2, 3, 4 and 5 show visual inspection of the EDA of the BRICS equity markets' price and return series. For each of the markets, it can be observed that plots of the daily equity prices are not stationary as displayed in panels $a, b$, e and $f$. These panels show the non-stationary trend of the raw price series plot, the density plot, QQ (quantile-quantile) plot and the box plot. On the other hand, panels c, $\mathrm{d}, \mathrm{g}$ and $\mathrm{h}$ display an approximate stationarity for the return series plot, the density plot, QQ plot and the box plot. Kernel density estimation is used to estimate the density [36]. The observations that are not aligned on the unit diagonal of the QQ plot at the extreme sides indicate extreme observations, hence the distribution is fat-tailed.

\subsection{Descriptive statistics}

The preliminary descriptive statistics for the BRICS equity prices and returns for the period under study are presented in Table 1. The table gives information on the sample mean, median, standard deviation, maximum, minimum, kurtosis, skewness, Jarque-Bera (JB) test and the corresponding $p$-values for the daily price and returns 
Table 1. Descriptive Statistics.

\begin{tabular}{|l|l|l|l|l|l|}
\hline INDEX & Brazil & Russia & India & China & South Africa \\
\hline Mean & 59766.72 & 40.21 & 122.21 & 433.65 & 4182.60 \\
\hline Median & 58369.76 & 40.20 & 120.35 & 432.64 & 4237.20 \\
\hline Maximum & 87652.64 & 66.23 & 174.78 & 832.07 & 5207.14 \\
\hline Minimum & 37497.48 & 19.90 & 78.12 & 314.68 & 2744.87 \\
\hline Std. Dev. & 9724.44 & 9.59 & 19.97 & 85.15 & 422.84 \\
\hline Skewness & 0.57 & 0.28 & 0.41 & 1.32 & -0.48 \\
\hline Kurtosis & 3.10 & 2.58 & 2.48 & 5.95 & 2.99 \\
\hline Jarque-Bera & 115.95 & 43.65 & 85.01 & 1388.51 & 82.76 \\
\hline Probability & 0.00 & 0.00 & 0.00 & 0.00 & 0.00 \\
\hline Observations & 2126 & 2126 & 2126 & 2126 & 2126 \\
\hline RETURNS & & & & & \\
\hline Mean & 0.01 & -0.01 & 0.02 & -0.01 & 0.01 \\
\hline Median & 0.02 & -0.01 & 0.06 & 0.05 & 0.05 \\
\hline Maximum & 6.39 & 13.67 & 6.20 & 5.57 & 6.46 \\
\hline Minimum & -9.21 & -13.30 & -7.51 & -9.15 & -7.62 \\
\hline Std. Dev. & 1.43 & 1.84 & 1.27 & 1.41 & 1.51 \\
\hline Skewness & -0.17 & -0.46 & -0.30 & -0.99 & -0.24 \\
\hline Kurtosis & 5.01 & 9.24 & 6.28 & 8.98 & 4.81 \\
\hline Jarque-Bera & 368.01 & 3525.34 & 983.30 & 3514.65 & 310.12 \\
\hline Probability & 0.00 & 0.00 & 0.00 & 0.00 & 0.00 \\
\hline Observations & 2126 & 2126 & 2126 & 2126 & 2126 \\
\hline
\end{tabular}

series. To begin with, the table shows that the Indian NIFTY index has the highest positive mean returns of 0.02, followed by the Brazilian Bovespa and South African JALSH, both of which have an approximate mean return of 0.01. Russian IMOEX and Chinese SHCOMP markets have an approximate negative expected return of -0.01 , indicating financial loss or negative return during the period under study.

The table also shows that the five markets return series are leptokurtic, i.e. their kurtosis are greater than 3 . This indicates that extreme price changes take place more frequently during the sampled period [35]. Kurtosis relates to the tails of a distribution, where the value 3 is associated with the kurtosis of a normal distribution. In addition, the table shows negative skewness for the five returns, implying that the market indices have long left tail distribution. Negative skewness also denotes higher probability of large decreases in equity returns for the period sampled. The BRIC's (excluding the South African index) daily prices on the other hand show positive skewness that signifies long right tail distributions. The skewness further indicates that the markets' distributions are non-normal. The non-normality is supported by the significance of the Jarque-Bera (JB) test statistic at $1 \%$ level for the prices and returns in the five indices.

\subsection{Test for stationarity}

Stationarity of the raw price and returns was evaluated using the Augmented-Dickey Fuller (ADF), Phillips-Perron (PP), and Kwiatkowski, Phillips, Schmidt, and Shin (KPSS) tests for unit root. The test was first implemented on the daily price index and it was found that the price indices are not stationary. This is in line with the visual inspections in Figures 1, 2, 3, 4 and 5.

Next, the raw price data were transformed to the returns by taking the first difference of logarithms of the price. After this, it is observed that in the ADF, PP and KPSS tests, the test statistics are less than the critical values at $1 \%, 5 \%$ and $10 \%$ levels of significance for the five BRICS markets as displayed in Table 2 . These results indicate 
Table 2. Unit root tests for the returns.

\begin{tabular}{|l|l|l|l|}
\hline RETURNS & \multicolumn{1}{|c|}{ ADF test } & \multicolumn{1}{c|}{ PP test } & \multicolumn{1}{c|}{ KPSS test } \\
\hline Brazil & Test statistic: -15.8791 & Test statistic: -46.2952 & Test statistic: 0.0261 \\
& $1 \%$ CV: -3.96 & $1 \%$ CV: -3.9677 & $1 \%$ CV: 0.216 \\
& 5\% CV: -3.41 & $5 \%$ CV: -3.4145 & 5\% CV: 0.146 \\
& $10 \%$ CV: -3.12 & $10 \%$ CV: -3.1290 & $10 \%$ CV: 0.119 \\
\hline Russia & Test statistic: -15.6789 & Test statistic: -43.0720 & Test statistic: 0.0589 \\
& $1 \%$ CV: -3.96 & $1 \%$ CV: -3.9677 & $1 \%$ CV: 0.216 \\
& $5 \%$ CV: -3.41 & $5 \%$ CV: -3.4145 & $5 \%$ CV: 0.146 \\
& $10 \%$ CV: -3.12 & $10 \%$ CV: -3.1290 & $10 \%$ CV: 0.119 \\
\hline India & Test statistic: -14.7871 & Test statistic: -43.4383 & Test statistic: 0.0272 \\
& $1 \%$ CV: -3.96 & $1 \%$ CV: -3.9677 & $1 \%$ CV: 0.216 \\
& $5 \%$ CV: -3.41 & $5 \%$ CV: -3.4145 & $5 \%$ CV: 0.146 \\
& $10 \%$ CV: -3.12 & $10 \%$ CV: -3.1290 & $10 \%$ CV: 0.119 \\
\hline China & Test statistic: -13.8347 & Test statistic: -44.3166 & Test statistic: 0.0923 \\
& $1 \%$ CV: -3.96 & $1 \%$ CV: -3.9677 & $1 \%$ CV: 0.216 \\
& $5 \%$ CV: -3.41 & $5 \%$ CV: -3.4145 & $5 \%$ CV: 0.146 \\
& $10 \%$ CV: -3.12 & $10 \%$ CV: -3.1290 & $10 \%$ CV: 0.119 \\
\hline South Africa & Test statistic: -16.7423 & Test statistic: -44.0049 & Test statistic: 0.0405 \\
& $1 \%$ CV: -3.96 & $1 \%$ CV: -3.9677 & $1 \%$ CV: 0.216 \\
& $5 \%$ CV: -3.41 & $5 \%$ CV: -3.4145 & $5 \%$ CV: 0.146 \\
& $10 \%$ CV: -3.12 & $10 \%$ CV: -3.1290 & $10 \%$ CV: 0.119 \\
\hline
\end{tabular}

CV is the critical value with levels of significance $1 \%, 5 \%$ and $10 \%$, at lag 8.

that the return series are stationary, since the null hypothesis of a unit root in the series is rejected under the ADF and PP tests, and the null hypothesis of stationarity cannot be rejected under the KPSS test at the three levels.

\subsection{Test for serial correlation}

Following stationarity of the data, it is required to test for the presence of short-range linear dependence termed serial correlation or autocorrelation in the residuals. Serial correlation may occur as a result of the relationship between a variable and its lagged version over various intervals of time. This test is carried out on both the price and return residuals using the Weighted Ljung-Box test [14]. The results are displayed under panels $(A)$ and $(B)$ in Table 3. For the price data, panel $(A)$ of the table shows all the $p$-values $<0.05$ at lags 1,5 and 9 for the standardized residuals of the BRICS equity markets, which denotes strong autocorrelation in the price data.

The price data were transformed to the log-returns and some candidates $\operatorname{ARMA}(p, q)$ models were fitted to the five BRICS markets' return series. From the candidate models, $\operatorname{ARMA}(1,1)$ model as stated in equation (33) is found to be the most suitable to remove linear dependency (autocorrelation) in the markets' returns series.

$$
r_{t}=\alpha_{o}+\alpha_{1} r_{t-1}+\varphi_{1} \varepsilon_{t-1}+\varepsilon_{t}
$$

Panel $(B)$ of Table 3 shows the outcome of the "Weighted Ljung-Box" test that relates to the selected ARMA(1, 1) model for each of the BRICS markets' returns. The $p$-values (at lags 1, 5 and 9) are big (greater than 0.05), hence we fail to reject the null hypothesis of "no serial correlation" in the return residuals. 
Table 3. Weighted Ljung-Box Test of Standardized Residuals.

\begin{tabular}{|c|c|c|c|c|c|c|}
\hline $\begin{array}{l}\text { (A) Brazil } \\
\text { Price residuals }\end{array}$ & Lag & Statistic & $P$-value & $\begin{array}{l}\text { (B) Brazil } \\
\text { Return residuals } \\
\text { with } \operatorname{ARMA}(1,1)\end{array}$ & Statistic & $P$-value \\
\hline & 1 & 1877 & 0.0000 & & 0.6367 & 0.4249 \\
\hline & 5 & 2767 & 0.0000 & & 1.6665 & 0.9932 \\
\hline & 9 & 5309 & 0.0000 & & 3.9328 & 0.7067 \\
\hline \multirow[t]{4}{*}{$\begin{array}{l}\text { (A) Russia } \\
\text { Price residuals }\end{array}$} & Lag & Statistic & $P$-value & $\begin{array}{l}\text { (B) Russia } \\
\text { Return residuals } \\
\text { with } \operatorname{ARMA}(1,1)\end{array}$ & Statistic & $P$-value \\
\hline & 1 & 1891 & 0.0000 & & 0.4741 & 0.4911 \\
\hline & 5 & 2780 & 0.0000 & & 0.5891 & 1.0000 \\
\hline & 9 & 5350 & 0.0000 & & 1.2519 & 0.9991 \\
\hline \multirow[t]{4}{*}{$\begin{array}{l}\text { (A) India } \\
\text { Price residuals }\end{array}$} & Lag & Statistic & $P$-value & $\begin{array}{l}\text { (B) India } \\
\text { Return residuals } \\
\text { with } \operatorname{ARMA}(1,1)\end{array}$ & Statistic & $P$-value \\
\hline & 1 & 2034 & 0.0000 & & 1.0270 & 0.3108 \\
\hline & 5 & 3027 & 0.0000 & & 1.8920 & 0.9749 \\
\hline & 9 & 5936 & 0.0000 & & 2.4840 & 0.9531 \\
\hline \multirow[t]{4}{*}{$\begin{array}{l}\text { (A) China } \\
\text { Price residuals }\end{array}$} & Lag & Statistic & $P$-value & $\begin{array}{l}\text { (B) China } \\
\text { Return residuals } \\
\text { with } \operatorname{ARMA}(1,1)\end{array}$ & Statistic & $P$-value \\
\hline & 1 & 2044 & 0.0000 & & 0.5674 & 0.4513 \\
\hline & 5 & 3047 & 0.0000 & & 2.3102 & 0.8677 \\
\hline & 9 & 5992 & 0.0000 & & 4.9254 & 0.4707 \\
\hline \multirow[t]{4}{*}{$\begin{array}{l}\text { (A) SouthAfrica } \\
\text { Price residuals }\end{array}$} & Lag & Statistic & $P$-value & $\begin{array}{l}\text { (B) SouthAfrica } \\
\text { Return residuals } \\
\text { with } \operatorname{ARMA}(1,1)\end{array}$ & Statistic & $P$-value \\
\hline & 1 & 1810 & 0.0000 & & 2.3370 & 0.1263 \\
\hline & 5 & 2661 & 0.0000 & & 3.2770 & 0.3100 \\
\hline & 9 & 5067 & 0.0000 & & 4.9960 & 0.4546 \\
\hline
\end{tabular}

Table 4. ARCH-LM Test.

\begin{tabular}{|l|l|l|l|l|l|}
\hline & Brazil & \multicolumn{1}{|c|}{ Russia } & India & China & South Africa \\
\hline & (Bovespa) & (IMOEX) & (NIFTY) & (SHCOMP) & (JALSH) \\
\hline $\begin{array}{l}\text { ARCH-LM test } \\
\text { statistic }\left[M R^{2}\right]\end{array}$ & 74.69051 & 146.3231 & 136.7945 & 275.4920 & 126.4324 \\
Prob. $-\chi^{2}(5)$ & $\{0.0000\}^{*}$ & $\{0.0000\}^{*}$ & $\{0.0000\}^{*}$ & $\{0.0000\}^{*}$ & $\{0.0000\}^{*}$ \\
\hline
\end{tabular}

* significant at $1 \%$ level. The value in (.) is the lag length and that in $\{$.$\} is the p-values. M R^{2}$ defines the LM test statistic for which $M$ is the number of observations and $R$ is the sample multiple correlation coefficient. 


\subsection{Test for ARCH effects}

Following the filtering of short-range dependence from the data series, it is next required to test for the presence of heteroscedasticity or ARCH effects in the data before fitting the GARCH model on the residuals of the return series. The presence of ARCH effects can be tested using ARCH LM Test.

Table 4 shows that the ARCH-LM test statistic in the five BRICS markets is highly significant with all the $p$ values very small (lower than 0.05), hence, the null hypothesis of "no ARCH effect" is strongly rejected in the residuals of the returns series. This result is a confirmation of the presence of ARCH effects in the residuals of the five indices, which indicates the existence of volatility clustering as a result of the time varying variances of the return series. Based on this, a GARCH model can be fitted to remove the ARCH effects in the series. The modelling and filtration of volatility (heteroscedasticity effects) of the returns will be implemented using candidate GARCH models under each of the selected error distributions.

\subsection{Empirical outcomes of the ARMA-GARCH models}

This section focuses on the volatility dynamics of the five BRICS markets to determine the magnitudes of volatility in each and arrange them from the highest to the lowest for investors' decision making. To begin with, several candidate $\operatorname{ARMA}(p, q)-\operatorname{GARCH}(k, v)$ models were run to obtain a combined model that can best remove linear dependency and heteroscedasticity in the return series. From the candidate models, $\operatorname{ARMA}(1,1)$ and GARCH(1, 1) are jointly selected as the most adequate for the Brazilian, Russian, Indian, Chinese and South African equity markets. The fitting of the joint ARMA-GARCH model is carried out under the selected error distributions of a normal, Student's $t$, GED (with their skew versions), and the GHYP.

Tables 5, 6, 7, and 8 show the empirical results (parameter estimates) of the $\operatorname{ARMA}(1,1)-\operatorname{GARCH}(1,1)$ under each of the stated error distributions. The evidence from the daily series in the five indices indicates that all the GARCH parameters (i.e. $\omega, \alpha$, and $\beta$ ) under all the error distributions are statistically significant at $1 \%$ level. The AIC, BIC, SIC and HQIC are jointly used for model selection under each of the best error distributions. Model selection is based on the values of the information criteria, where the least values are indicative of the best model, under a given error assumption.

\subsection{Residual diagnostic test}

After fitting the GARCH models to the returns, residual diagnostics were carried out with the use of the weighted ARCH LM tests to determine whether ARCH (heteroscedastic) effects have been filtered out of the residuals or not. The results from the "ARCH LM test statistic (5)" in Table 4 show that at lag order 5, under all the stated error distributions, the $p$-values are sufficiently large (above 5\%) for the five BRICS markets. Based on this, we fail to reject the null hypothesis of "no ARCH effect" in the residuals, and hence conclude that the variance equations are well specified.

From Tables 5, 6, 7, and 8, for the Brazilian market, all the four information criteria have their least values under the Student's $t$ innovations of the $\operatorname{ARMA}(1,1)-\operatorname{GARCH}(1,1)$ model. This indicates that the Brazilian Bovespa market's volatility can be best described by an $\operatorname{ARMA}(1,1)-\operatorname{GARCH}(1,1)$ model using the Student's $t$ distribution. For the Russian market also, all the information criteria have their least values under the Student's $t$ innovations of the ARMA-GARCH model (like the Brazilian market). Hence, it is concluded that volatility of the Russian IMOEX market can be best characterized by an $\operatorname{ARMA}(1,1)-\operatorname{GARCH}(1,1)$ model under the Student's $t$ distribution.

In the Indian NIFTY market, both the AIC and SIC have their least values under the GHYP distribution, while the BIC and HQIC have their least values under the Student's $t$ and skew-Student's $t$ distributions respectively. However, since the values of the $\{\mathrm{AIC}=\mathrm{SIC}\}<\{\mathrm{HQIC}\}<\{\mathrm{BIC}\}$ (see Tables 5, 7 and 8), it is concluded that the Indian NIFTY market's volatility can be best characterized by an $\operatorname{ARMA}(1,1)-\operatorname{GARCH}(1,1)$ model under the GHYP distribution using the AIC-SIC's least values. For the Chinese SHCOMP market, all the information criteria have their least values under the skew-GED innovations, which therefore indicates that it is the best distribution assumption to characterize the market's volatility under the $\operatorname{ARMA}(1,1)-\operatorname{GARCH}(1,1)$ model. Lastly, for the South African JALSH market, all the information criteria have their least values under the skew-Student's $t$ innovations. 
Table 5. Estimated result of ARMA-GARCH model.

\begin{tabular}{|c|c|c|c|c|c|}
\hline $\begin{array}{l}\text { ARMA }(1,1)-\operatorname{GARCH}(1,1) \\
\text { under "normal } \\
\text { distribution" assumption }\end{array}$ & & & & & \\
\hline & $\begin{array}{l}\text { Brazil } \\
\text { (Bovespa) }\end{array}$ & $\begin{array}{l}\text { Russia } \\
\text { (IMOEX) }\end{array}$ & $\begin{array}{l}\text { India } \\
\text { (NIFTY) }\end{array}$ & $\begin{array}{l}\text { China } \\
\text { (SHCOMP) }\end{array}$ & $\begin{array}{l}\text { S/Africa } \\
\text { (JALSH) }\end{array}$ \\
\hline \multicolumn{6}{|l|}{ Coefficients } \\
\hline & Mean & & & & \\
\hline \multirow[t]{2}{*}{$\hat{\mu}$ (constant) } & $0.0268 * * *$ & $0.0487 * * *$ & $0.0556^{*}$ & $0.0083 * * *$ & $0.0210 * * *$ \\
\hline & Variance & & & & \\
\hline$\hat{\omega}$ & $0.0821 *$ & $0.0737 *$ & $0.0225^{*}$ & $0.0062 *$ & $0.0257 *$ \\
\hline$\hat{\alpha}$ & $0.0657 *$ & $0.0732 *$ & $0.0693 *$ & $0.0480 *$ & $0.0493 *$ \\
\hline$\hat{\beta}$ & $0.8943 *$ & $0.9063 *$ & $0.9176^{*}$ & $0.9502 *$ & $0.9398 *$ \\
\hline$\hat{\alpha}+\hat{\beta}$ & 0.9600 & 0.9795 & 0.9869 & 0.9982 & 0.9891 \\
\hline $\mathrm{AIC}$ & 3.4903 & 3.8767 & 3.1663 & 3.2220 & 3.5489 \\
\hline BIC & 3.5063 & 3.8927 & 3.1822 & 3.2379 & 3.5649 \\
\hline SIC & 3.4903 & 3.8767 & 3.1662 & 3.2219 & 3.5489 \\
\hline HQIC & 3.4962 & 3.8825 & 3.1721 & 3.2278 & 3.5548 \\
\hline ARCH LM test statistic (5) & 0.7027 & 0.1583 & 0.4248 & 1.3510 & 0.9846 \\
\hline$p$-value (5) & $(0.8226)$ & $(0.9750)$ & $(0.9056)$ & $(0.6325)$ & $(0.7375)$ \\
\hline \multicolumn{6}{|l|}{$\begin{array}{l}\text { ARMA(1,1)-GARCH(1,1) } \\
\text { under "Student's } t \\
\text { distribution" assumption }\end{array}$} \\
\hline \multicolumn{6}{|l|}{ Coefficients } \\
\hline & Mean & & & & \\
\hline \multirow[t]{2}{*}{$\hat{\mu}$ (constant) } & $0.0289 * * *$ & $0.0320 * * *$ & $0.0616^{*}$ & $0.0411 * *$ & $0.0339 * * *$ \\
\hline & Variance & & & & \\
\hline$\hat{\omega}$ & $0.0623 *$ & $0.0335^{*}$ & $0.0202^{*}$ & $0.0106^{*}$ & $0.0251 *$ \\
\hline$\hat{\alpha}$ & $0.0571^{*}$ & $0.0600^{*}$ & $0.0626^{*}$ & $0.0523^{*}$ & $0.0496 *$ \\
\hline$\hat{\beta}$ & $0.9120 *$ & $0.9298 *$ & $0.9256^{*}$ & $0.9443^{*}$ & $0.9399 *$ \\
\hline$\hat{\alpha}+\hat{\beta}$ & 0.9691 & 0.9898 & 0.9882 & 0.9966 & 0.9895 \\
\hline AIC & 3.4664 & 3.7844 & 3.1302 & 3.1501 & 3.5298 \\
\hline BIC & 3.4851 & 3.8030 & 3.1488 & 3.1688 & 3.5484 \\
\hline SIC & 3.4664 & 3.7843 & 3.1302 & 3.1501 & 3.5297 \\
\hline HQIC & 3.4733 & 3.7912 & 3.1370 & 3.1570 & 3.5366 \\
\hline ARCH LM test statistic (5) & 0.3741 & 0.1038 & 0.4484 & 1.4610 & 0.9945 \\
\hline$p$-value (5) & $(0.9200)$ & $(0.9861)$ & $(0.8987)$ & $(0.6026)$ & $(0.7346)$ \\
\hline
\end{tabular}

Note: “*”, “**” and “***” are 1\%, 5\% and 10\% levels of significance respectively. ARCH LM test statistic (5) denotes ARCH effects up to the $5^{\text {th }}$ order with p-values in parentheses, and $5 \%$ level of significance is used in every case.

Hence, volatility of the South African market is best described by the $\operatorname{ARMA}(1,1)-\operatorname{GARCH}(1,1)$ model under the skew-Student's $t$ distribution.

As a summary, it is concluded that using the $\operatorname{ARMA}(1,1)-\operatorname{GARCH}(1,1)$ model, volatilities of the Brazilian Bovespa and the Russian IMOEX markets can both be well characterized (or described) by a heavy-tailed Student's 
Table 6. Estimated result of ARMA-GARCH model.

\begin{tabular}{|c|c|c|c|c|c|}
\hline $\begin{array}{l}\text { ARMA }(1,1)-\operatorname{GARCH}(1,1) \\
\text { under "generalized error } \\
\text { distribution" (GED) } \\
\text { assumption }\end{array}$ & & & & & \\
\hline & $\begin{array}{l}\text { Brazil } \\
\text { (Bovespa) }\end{array}$ & $\begin{array}{l}\text { Russia } \\
\text { (IMOEX) }\end{array}$ & $\begin{array}{l}\text { India } \\
\text { (NIFTY) }\end{array}$ & $\begin{array}{l}\text { China } \\
\text { (SHCOMP) }\end{array}$ & $\begin{array}{l}\text { S/Africa } \\
\text { (JALSH) }\end{array}$ \\
\hline \multicolumn{6}{|l|}{ Coefficients } \\
\hline & Mean & & & & \\
\hline \multirow[t]{2}{*}{$\hat{\mu}($ constant $)$} & $0.0281 * * *$ & $0.0221 * * *$ & $0.0672 *$ & $0.0413 *$ & $0.0372 * * *$ \\
\hline & Variance & & & & \\
\hline$\hat{\omega}$ & $0.0722 *$ & $0.0450 *$ & $0.0207^{*}$ & $0.0089 *$ & $0.0285 *$ \\
\hline$\hat{\alpha}$ & $0.0610^{*}$ & $0.0637 *$ & $0.0646^{*}$ & $0.0502 *$ & $0.0496 *$ \\
\hline$\hat{\beta}$ & $0.9036^{*}$ & $0.9233 *$ & $0.9229 *$ & $0.9458 *$ & $0.9378 *$ \\
\hline$\hat{\alpha}+\hat{\beta}$ & 0.9646 & 0.9870 & 0.9875 & 0.9960 & 0.9874 \\
\hline $\mathrm{AIC}$ & 3.4711 & 3.8091 & 3.1303 & 3.1459 & 3.5342 \\
\hline $\mathrm{BIC}$ & 3.4897 & 3.8278 & 3.1489 & 3.1645 & 3.5529 \\
\hline SIC & 3.4710 & 3.8091 & 3.1303 & 3.1459 & 3.5342 \\
\hline HQIC & 3.4779 & 3.8160 & 3.1371 & 3.1527 & 3.5411 \\
\hline ARCH LM test statistic (5) & 0.5283 & 0.1230 & 0.3915 & 1.4830 & 1.0515 \\
\hline$p$-value (5) & $(0.8752)$ & $(0.9824)$ & $(0.9151)$ & $(0.5968)$ & $(0.7177)$ \\
\hline \multicolumn{6}{|l|}{$\begin{array}{l}\text { under "skew - normal } \\
\text { distribution" assumption }\end{array}$} \\
\hline \multicolumn{6}{|l|}{ Coefficients } \\
\hline & Mean & & & & \\
\hline \multirow[t]{2}{*}{$\hat{\mu}($ constant $)$} & $0.0225 * * *$ & $0.0218 * * *$ & $0.0478 * *$ & $-0.0057 * * *$ & $0.0126 * * *$ \\
\hline & Variance & & & & \\
\hline$\hat{\omega}$ & $0.0775 *$ & $0.0667 *$ & $0.0210 *$ & $0.0076 *$ & $0.0243 *$ \\
\hline$\hat{\alpha}$ & $0.0645^{*}$ & $0.0675^{*}$ & $0.0657 *$ & $0.0484 *$ & $0.0495 *$ \\
\hline$\hat{\beta}$ & $0.8976^{*}$ & $0.9129 *$ & $0.9216^{*}$ & $0.9483 *$ & $0.9400 *$ \\
\hline$\hat{\alpha}+\hat{\beta}$ & 0.9621 & 0.9804 & 0.9873 & 0.9967 & 0.9895 \\
\hline AIC & 3.4895 & 3.8665 & 3.1639 & 3.2101 & 3.5410 \\
\hline BIC & 3.5081 & 3.8852 & 3.1825 & 3.2287 & 3.5597 \\
\hline SIC & 3.4895 & 3.8665 & 3.1639 & 3.2100 & 3.5410 \\
\hline HQIC & 3.4963 & 3.8734 & 3.1707 & 3.2169 & 3.5478 \\
\hline ARCH LM test statistic (5) & 0.6653 & 0.1262 & 0.4315 & 1.2450 & 0.9522 \\
\hline$p$-value (5) & $(0.8340)$ & $(0.9818)$ & $(0.9036)$ & $(0.6619)$ & $(0.7472)$ \\
\hline
\end{tabular}

Note: “*”, “**” and “***” are 1\%, 5\% and 10\% levels of significance respectively. ARCH LM test statistic (5) denotes ARCH effects up to the $5^{\text {th }}$ order with p-values in parentheses, and $5 \%$ level of significance is used in every case.

$t$ distribution, while the Indian NIFTY market's volatility is best characterized by the GHYP distribution. Also, the Chinese SHCOMP and South African JALSH markets' volatilities are best described by the skew-GED and skewStudent's $t$ distribution respectively. This outcome is consistent with the findings of Romero and Kasibhatla [33] who studied the volatility dynamics of the BRIC (excluding South Africa) from 2000 to 2010 using GARCH 
Table 7. Estimated result of ARMA-GARCH model.

\begin{tabular}{|c|c|c|c|c|c|}
\hline $\begin{array}{l}\operatorname{ARMA}(1,1)-\operatorname{GARCH}(1,1) \\
\text { under "skew - Student's } t \\
\text { distribution" assumption }\end{array}$ & & & & & \\
\hline & $\begin{array}{l}\text { Brazil } \\
\text { (Bovespa) }\end{array}$ & $\begin{array}{l}\text { Russia } \\
\text { (IMOEX) }\end{array}$ & $\begin{array}{l}\text { India } \\
\text { (NIFTY) }\end{array}$ & $\begin{array}{l}\text { China } \\
\text { (SHCOMP) }\end{array}$ & $\begin{array}{l}\text { S/Africa } \\
\text { (JALSH) }\end{array}$ \\
\hline \multicolumn{6}{|l|}{ Coefficients } \\
\hline & Mean & & & & \\
\hline \multirow[t]{2}{*}{$\hat{\mu}$ (constant) } & $0.0246 * * *$ & $0.0241 * * *$ & $0.0430 * *$ & $0.0147 * * *$ & $0.0116 * * *$ \\
\hline & Variance & & & & \\
\hline$\hat{\omega}$ & $0.0619 *$ & $0.0332^{*}$ & $0.0196 *$ & $0.0107 *$ & $0.0241^{*}$ \\
\hline$\hat{\alpha}$ & $0.0569 *$ & $0.0593^{*}$ & $0.0623 *$ & $0.0522 *$ & $0.0503 *$ \\
\hline$\hat{\beta}$ & $0.9124^{*}$ & $0.9303^{*}$ & $0.9261 *$ & $0.9437 *$ & $0.9396^{*}$ \\
\hline$\hat{\alpha}+\hat{\beta}$ & 0.9693 & 0.9896 & 0.9884 & 0.9959 & 0.9899 \\
\hline AIC & 3.4672 & 3.7850 & 3.1283 & 3.1476 & 3.5241 \\
\hline BIC & 3.4885 & 3.8063 & 3.1496 & 3.1689 & 3.5454 \\
\hline SIC & 3.4672 & 3.7850 & 3.1283 & 3.1475 & 3.5241 \\
\hline HQIC & 3.4750 & 3.7928 & 3.1361 & 3.1554 & 3.5319 \\
\hline ARCH LM test statistic (5) & 0.3678 & 0.1021 & 0.4492 & 1.2468 & 0.9660 \\
\hline$p$-value (5) & $(0.9218)$ & $(0.9864)$ & $(0.8985)$ & $(0.6614)$ & $(0.7431)$ \\
\hline \multicolumn{6}{|l|}{$\begin{array}{l}\text { ARMA }(1,1)-G A R C H(1,1) \\
\text { under "skew - GED } \\
\text { distribution" } \\
\text { assumption }\end{array}$} \\
\hline \multicolumn{6}{|l|}{ Coefficients } \\
\hline & Mean & & & & \\
\hline \multirow[t]{2}{*}{$\hat{\mu}$ (constant) } & $0.0193 * * *$ & $0.0079 * * *$ & $0.0453 * *$ & $0.00028 * * *$ & $0.0117 * * *$ \\
\hline & Variance & & & & \\
\hline$\hat{\omega}$ & $0.0688^{*}$ & $0.0446 *$ & $0.0202 *$ & $0.0098 *$ & $0.0262 *$ \\
\hline$\hat{\alpha}$ & $0.0599 *$ & $0.0624^{*}$ & $0.0633^{*}$ & $0.0505^{*}$ & $0.0509 *$ \\
\hline$\hat{\beta}$ & $0.9062 *$ & $0.9242 *$ & $0.9241 *$ & $0.9446^{*}$ & $0.9377 *$ \\
\hline$\hat{\alpha}+\hat{\beta}$ & 0.9661 & 0.9866 & 0.9874 & 0.9951 & 0.9886 \\
\hline AIC & 3.4712 & 3.8094 & 3.1285 & 3.1411 & 3.5278 \\
\hline BIC & 3.4925 & 3.8307 & 3.1498 & 3.1624 & 3.5491 \\
\hline SIC & 3.4711 & 3.8093 & 3.1285 & 3.1411 & 3.5278 \\
\hline HQIC & 3.4790 & 3.8172 & 3.1363 & 3.1489 & 3.5356 \\
\hline ARCH LM test statistic (5) & 0.4955 & 0.1192 & 0.4189 & 1.1673 & 0.9983 \\
\hline$p$-value (5) & $(0.8849)$ & $(0.9832)$ & $(0.9073)$ & $(0.6840)$ & $(0.7334)$ \\
\hline
\end{tabular}

Note: “*”, “**” and “***” are 1\%, 5\% and 10\% levels of significance respectively. ARCH LM test statistic (5) denotes ARCH effects up to the $5^{\text {th }}$ order with p-values in parentheses, and $5 \%$ level of significance is used in every case.

models under the assumptions of three distributions of a normal, Student's $t$, and GED. That is, similar to our findings, the authors also concluded that the Student's $t$ error distribution was the best to describe the volatility of the Brazilian and Russian stock markets. However, since we used a wider scope of error distributions, i.e. we used 
Table 8. Estimated result of ARMA-GARCH model.

\begin{tabular}{|l|l|l|l|l|l|}
\hline $\begin{array}{l}\text { ARMA(1,1)-GARCH(1, } \\
\text { under "GHYP } \\
\text { distribution" assumption }\end{array}$ & & & & & \\
\hline & $\begin{array}{l}\text { Brazil } \\
\text { (Bovespa) }\end{array}$ & $\begin{array}{l}\text { Russia } \\
\text { (IMOEX) }\end{array}$ & $\begin{array}{l}\text { India } \\
\text { (NIFTY) }\end{array}$ & $\begin{array}{l}\text { China } \\
\text { (SHCOMP) }\end{array}$ & $\begin{array}{l}\text { S/Africa } \\
\text { (JALSH) }\end{array}$ \\
\hline Coefficients & & & & & \\
\hline & Mean & & & & \\
\hline$\hat{\mu}$ (constant) & $0.0217^{* * *}$ & $0.0122^{* * *}$ & $0.0451^{* *}$ & $0.0045^{* * *}$ & $0.0098^{* * *}$ \\
\hline & Variance & & & & \\
\hline$\hat{\omega}$ & $0.0622^{*}$ & $0.0332^{*}$ & $0.0196^{*}$ & $0.0102^{*}$ & $0.0240^{*}$ \\
\hline$\hat{\alpha}$ & $0.0568^{*}$ & $0.0582^{*}$ & $0.0626^{*}$ & $0.0507^{*}$ & $0.0496^{*}$ \\
\hline$\hat{\beta}$ & $0.9123^{*}$ & $0.9312^{*}$ & $0.9253^{*}$ & $0.9442^{*}$ & $0.9401^{*}$ \\
\hline$\hat{\alpha}+\hat{\beta}$ & 0.9691 & 0.9894 & 0.9879 & 0.9949 & 0.9897 \\
\hline AIC & 3.4678 & 3.7847 & 3.1281 & 3.1431 & 3.5252 \\
\hline BIC & 3.4917 & 3.8087 & 3.1521 & 3.1670 & 3.5492 \\
\hline SIC & 3.4677 & 3.7847 & 3.1281 & 3.1430 & 3.5252 \\
\hline HQIC & 3.4765 & 3.7935 & 3.1369 & 3.1518 & 3.5340 \\
\hline ARCH LM test statistic $(5)$ & 0.3627 & 0.0978 & 0.4318 & 1.1990 & 0.9815 \\
\hline$p$-value $(5)$ & $(0.9232)$ & $(0.9872)$ & $(0.9035)$ & $(0.6749)$ & $(0.7384)$ \\
\hline
\end{tabular}

Note: “*”, “**” and “***” are 1\%, 5\% and 10\% levels of significance respectively. ARCH LM test statistic (5) denotes ARCH effects up to the $5^{\text {th }}$ order with p-values in parentheses, and $5 \%$ level of significance is used in every case.

Table 9. The BRICS volatility hierarchy.

\begin{tabular}{|c|c|c|c|c|c|}
\hline & Most volatile & Next & Next & Next & Least volatile \\
\hline $\begin{array}{l}\text { Error } \\
\text { distributions }\end{array}$ & & & & & \\
\hline Student's $t$ & Chinese & Russian & South African & Indian & Brazilian \\
\hline Skew-student's $t$ & Chinese & South African & Russian & Indian & Brazilian \\
\hline GHYP & Chinese & South African & Russian & Indian & Brazilian \\
\hline GED & Chinese & Indian & South African & Russian & Brazilian \\
\hline Skew-GED & Chinese & South African & Indian & Russian & Brazilian \\
\hline
\end{tabular}

seven error distributions (including the skewed version and GHYP) as compared to their only three distributions, our study shows skew-GED and GHYP as the best distributions to describe the Chinese and Indian markets contrary to their choice of GED and Student's $t$ respectively.

\subsection{Densities and QQ diagnostic plots of the ARMA-GARCH models}

Figures 6, 7, 8, 9 and 10 show the densities of the standardized residuals and diagnostic quantile-quantile (QQ) plots of the ARMA $(1,1)-\operatorname{GARCH}(1,1)$ model under each of the best error distribution that describes each market. The QQ plots under each of the innovations display suitable levels of linearity since the points are well aligned on the straight lines, except at the tails (which denotes extreme movement). Furthermore, the plots of the densities 
of the standardized residuals confirm that each of the best error distributions (i.e., the Student's $t$, GHYP, skewStudent's $t$ and skew-GED) is a better fit to the distributions of the BRICS markets' return residuals than a normal distribution.
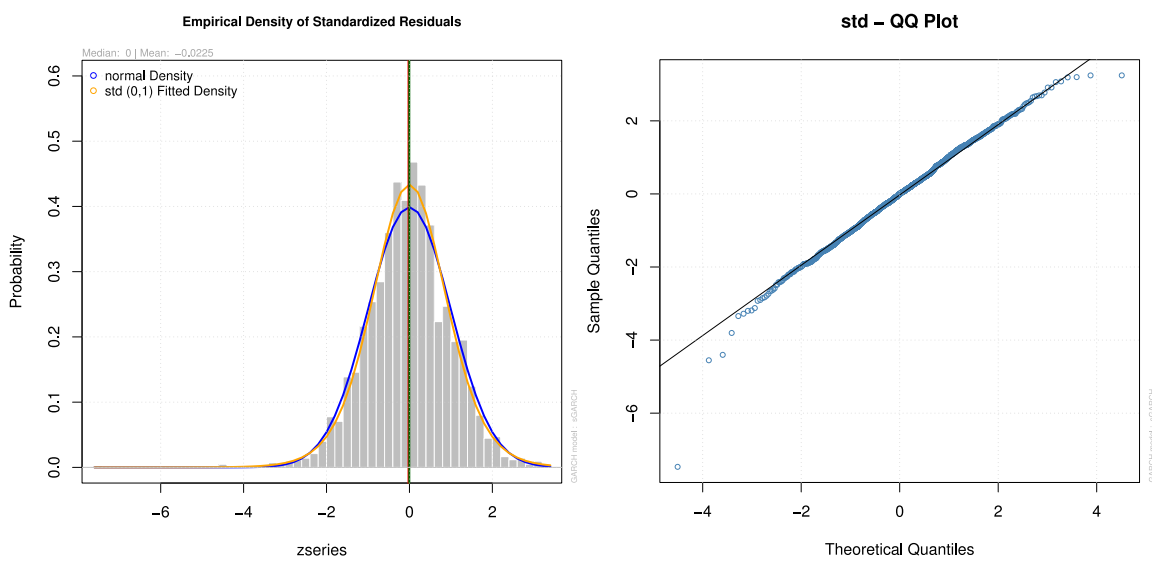

Figure 6. (a) Top panel: Return's residuals with Student's $t$ and normal densities (b) Bottom panel: Student's $t$ QQ plot for Bovespa index (Brazil).
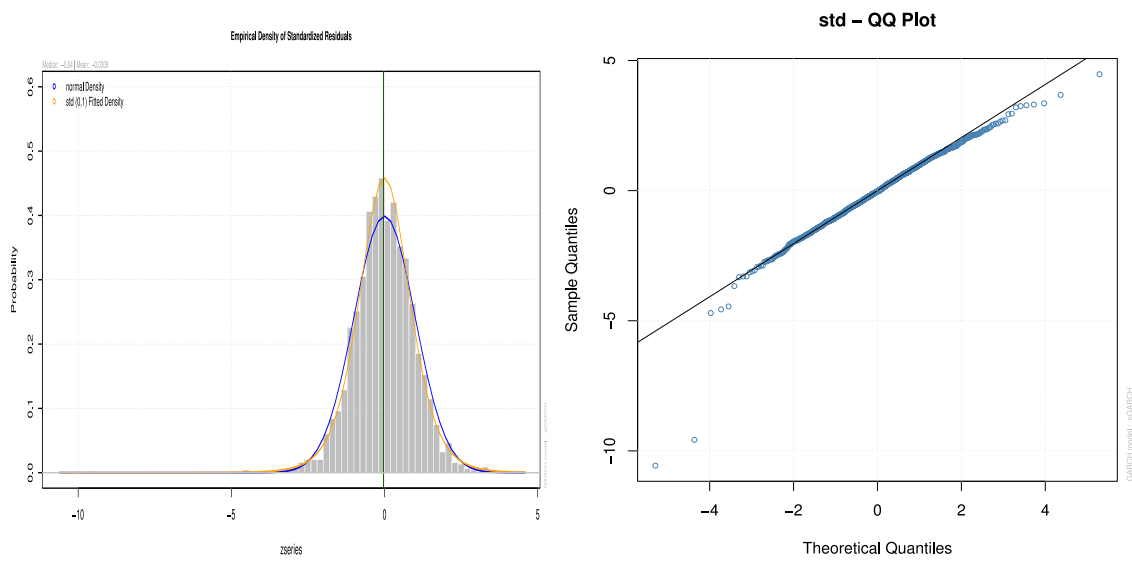

Figure 7. (a) Top panel: Return's residuals with Student's $t$ and normal densities (b) Bottom panel: Student's $t$ QQ plot for IMOEX index (Russia).

\section{Persistence of volatility}

We measure the persistence of volatility in the BRICS markets using the sum of the coefficients $(\alpha, \beta)$ in the conditional variance equation of the GARCH process, which is used to measure the speed of decay of shocks to volatility. This is referred to as the persistence of the GARCH model, and it indicates how fast large volatilities decline after a shock. Shocks to the conditional variability are highly persistent when the sum is greater than one $(\alpha$ $+\beta>1$ ), suggesting that the forecasts of volatility are explosive. This implies the presence of volatility clustering in the series. If the sum of the coefficients equals one (i.e. $\alpha+\beta=1$ ), then the persistence of shocks to volatility 

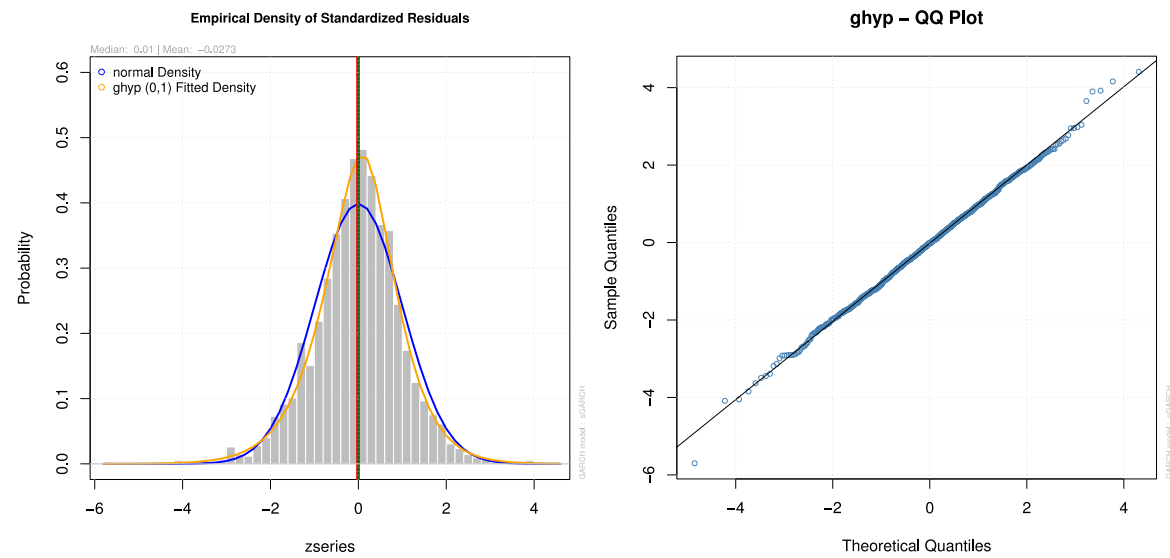

Figure 8. (a) Top panel: Return's residuals with GHYP and normal densities (b) Bottom panel: GHYP QQ plot for NIFTY index (India).
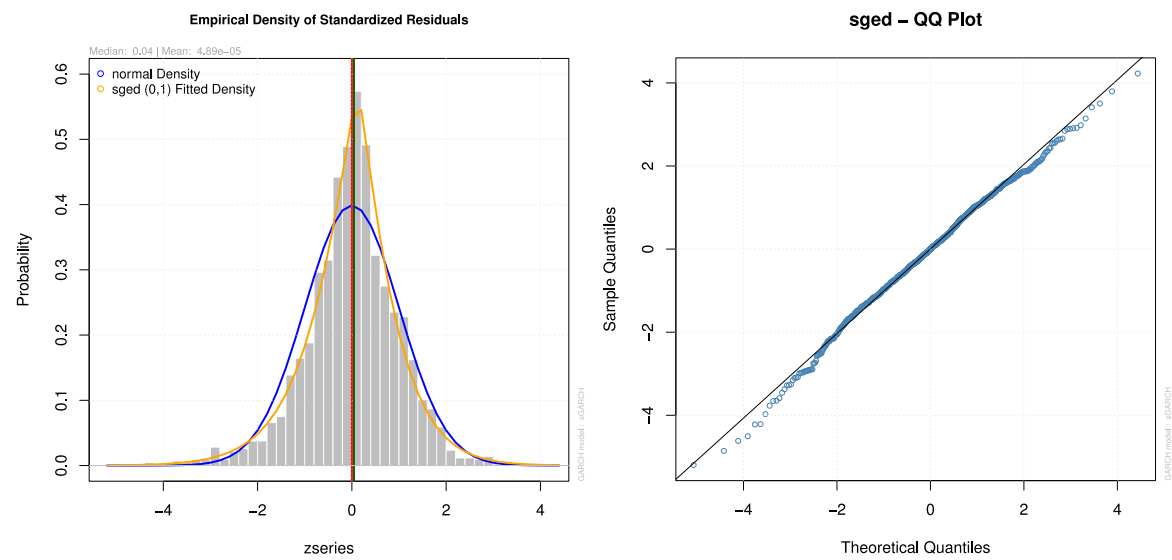

Figure 9. (a) Top panel: Return's residuals with skew-GED and normal densities (b) Bottom panel: Skew-GED QQ plot for SHCOMP index (China).
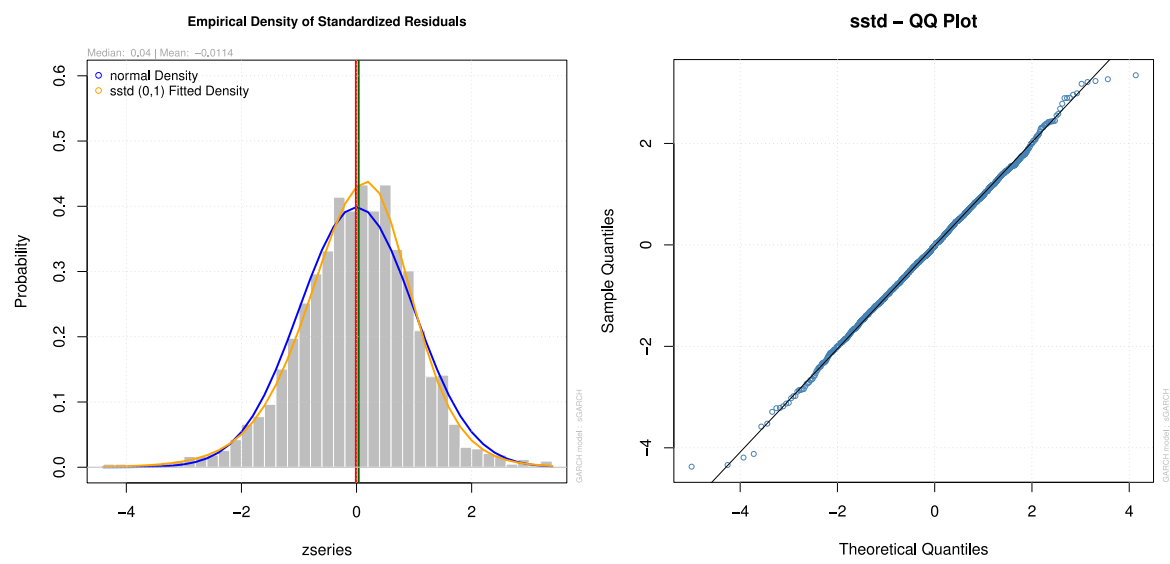

Figure 10. (a) Top panel: Return's residuals with skew-student's $t$ and normal densities (b) Bottom panel: Skew-student's $t$ QQ plot for JALSH index (South Africa). 
is felt forever, and the model will be unable to determine the unconditional variance of the process. Engle and Bollerslev [6] refer to this type of process as "Integrated-GARCH".

Lastly, shocks to volatility displays long persistence into the future if the sum $(\alpha+\beta)$ is close to one. This occurs because the variance process reverts very slowly to the mean (normal) state in a process termed "mean reversion". The closer the sum $(\alpha+\beta)$ to 1 , the longer it takes volatility to revert to the mean state.

\section{Conclusion: Volatility hierarchy of the BRICS equity markets}

The pattern of volatility persistence in each of the BRICS markets can be determined by a non-Gaussian distribution like the GED, Student's $t$ and GHYP. Financial returns are known to exhibit fat tails or leptokurtosis, and Gaussian distributions like the normal distribution is not suitable for modelling such [28].

The values of volatility persistence, i.e. the sum of the coefficients $(\alpha+\beta)$, at various magnitudes is close to one under the Student's $t$, skew-Student's $t$, GED, skew-GED and GHYP distribution (see Tables 5, 6, 7, and 8). The volatility hierarchy of the BRICS equity markets is evaluated based on the relative outcome of the sum of the coefficients, where the highest summation gives the highest volatility persistence. The volatility persistence obtained from summing the coefficients in the tables are summarized in Table 9. From this summary, it can be observed that the persistence of volatility in the BRICS markets does not follow the same hierarchical pattern under the error distributions, except under the skew-Student's $t$ and GHYP distributions where the pattern is the same. Under these two assumptions, i.e. the skew-Student's $t$ and GHYP, in a descending hierarchical order of magnitudes, volatility with persistence is highest in the Chinese market, followed by the South African market, then the Russian, Indian and Brazilian markets respectively (see Table 9).

For the Student's $t$ distribution, the Chinese market has the highest volatility persistence, followed by the Russian, South African, Indian and Brazilian markets in that order. For the GED, the pattern of the volatility persistence in a descending hierarchy is the Chinese, Indian, South African, Russian and Brazilian markets respectively. Lastly, for the skew-GED, the descending hierarchical pattern is the Chinese, South African, Indian, Russian and Brazilian markets respectively. However, under each of the error distributions, the Chinese market is the most volatile, while the least volatile is the Brazilian market.

This result is consistent with the findings of Ijumba [20] who also modelled the BRICS volatility, and observed the presence of volatility persistence in all the BRICS markets' stock returns using VAR and GARCH $(1,1)$ models. The study by the author also showed that Chinese market is the most volatile among the bloc but his conclusion on South African market being the least volatile market contradicts our findings of Brazil as the least volatile. The contradiction may be attributed to the scope and frequency of the data used for the two studies. The author [20] used sampled weekly data from 2000 to 2012, while our study used daily closing data from 2010 to 2018, and it should be noted that South Africa only joined the BRICS bloc in 2010. Hence, the author only had access to two years weekly data for the South African JSE whereas our study utilized eight years of daily closing South African JALSH data with wider coverage and much more market activities.

Based on the above findings, the main potential contribution of this paper to the growing studies on the volatility of the BRICS stock returns is twofold. First, this study gives new insights into the literature by providing a more robust explanation in more depth to the modelling and analysis of volatility of the BRICS stock returns by using the specified collective seven error distributions which as far as we know has not been done before this study. Second, as opposed to a major study carried out by Ijumba [20] for the entire five BRICS markets using weekly data that covered only 2 years of markets' activities from 2010 to 2012, our study used a wider coverage of activities from 2010 to 2018 using daily closing data, which can potentially give more accurate results.

\section{Acknowledgment}

The authors are grateful to the numerous people for helpful comments on this paper. 


\section{REFERENCES}

1. G. Adua, P. Alagidede, and A. Karimu, Stock return distribution in the BRICS, Review of Development Finance Vol. 5, pp. 98-109, 2015.

2. S. Ashour, and M. Abdel-Hameed, Approximate skew normal distribution, Journal of Advanced Research, vol. 1, pp. 341-350, 2010.

3. A. A. Azzalini, Class of distributions which includes the normal ones, Scand J Stat, pp. 171-178, 1985.

4. A. Azzalini, and A. Capitanio, Distributions generated by perturbation of symmetry with emphasis on a multivariate skew-t distribution, J. R. Stat. Soc. Ser. B, vol. 65, pp. 367-389, 2003.

5. O. Barndorff-Nielsen, Exponentially decreasing distributions for the logarithm of particle size, Proceedings of the Royal Society of London, 1977.

6. T. Bollerslev, Generalized autoregressive conditional heteroscedasticity, Journal of Econometrics, 31, 307-327, 1986.

7. M. D. Branco, and D. K. Dey, A general class of multivariate skew-elliptical distributions, Journal of Multivariate Analysis, 99-113, 2001.

8. W. Christensen, Model Selection Using Information Criteria (Made Easy in SAS?), University of California, Los Angeles, wchristensen@ucla.edu., https://github.com/wendychristensen, 2018.

9. M. Eling, Fitting asset returns to skewed distributions: Are the skew-normal and skew-student good models?, Insurance: Mathematics and Economics, vol. 59, pp. 45-56, 2014.

10. M. Emerson, Do the BRICS Make a Bloc, CEPS Commentary, https://www.ceps.eu/ceps-publications/do-brics-make-bloc/, 2012.

11. R. Engle, Autoregressive conditional heteroscedasticity with estimates of the variance of United Kingdom inflation, Econometrica, vol. 50, pp. 987-1006, 1982.

12. R. Engle, GARCH 101: the use of ARCH/GARCH models in applied econometrics, Journal of Economic Perspectives, vol. 15, pp. $157-168,2001$.

13. R. Engle, and T. Bollerslev, Modelling the persistence of conditional variances, Econometric Reviews, vol. 5, pp. 1-50, 1986.

14. T. J. Fisher, and C. M. Gallagher, New weighted portmanteau statistics for time series goodness of fit testing, Journal of the American Statistical Association, vol. 107, pp. 777-787, 2012.

15. G. Galloppo, V. Paimanova, and M. Aliano, Volatility and Liquidity in Eastern Europe Financial Markets under Efficiency and Transparency Conditions, Economics and Sociology, vol. 8, pp. 70-92, 2015.

16. A. Ghalanos, Introduction to the rugarch package (version 1.3-1), from https://cran.rproject.org/web/packages/rugarch/vignettes/Introduction to the rugarch package.pdf, 2015.

17. T. Grieb, and M. G. Reyes, Random walk tests for Latin American equity indexes and individual firms, Journal of Financial Research, vol. 22, pp. 371-383, 1999.

18. E. L. Hamaker, H. P. Van, R. M. Kuiper, and H. Hoijtink, Model selection based on information criteria in multilevel modeling, in Hox, J. J. \& Roberts, J. K (Eds.), Handbook of advanced multilevel analysis, pp. 231-255, 2011.

19. H. Herwartz, and C. M. Hafner, A Lagrange multiplier test for causality in variance, Economics Letters, vol. 93, pp. 137-141, 2006.

20. C. Ijumba, Multivariate analysis of the BRICS financial markets from http://hdl.handle.net/10413/11309, (Unpublished master's thesis), University of KwaZulu-Natal, South Africa, 2013.

21. IMF (International Monetary Fund), World Economic Outlook, Hopes, Realities, Risks, from http://www.imf.org/external/pubs/ft/weo/2013/01/pdf/text.pdf., 2013.

22. S. Javed, B. A. Aldalaien, and U. Husain, Volatility and analysis of BRICS stocks, Journal of Business \& Financial Affairs, from https://www.hilarispublisher.com/business-and-management-journals.html, ISSN: 2167-0234, Vol. 9, 2020.

23. R. E. Kennedy, and J. L. Sharma, A comparative analysis of stock price behaviour of the Bombay, London and New York stock exchanges, Journal of Financial and Quantitative Analysis, vol. 12, pp. 391-413, 1977.

24. Y. H. Lee, and T. Y. Pai, REIT volatility prediction for skew-GED distribution of the GARCH model, Expert Systems with Applications, Cardiff, vol. 37, pp. 4737-4741, 2010.

25. F. Li, A. S. Cohen, S. Kim, and S. Cho, Model Selection Methods for Mixture Dichotomous IRT Models, Applied Psychological Measurement, vol. 33, pp. 353-373, 2009.

26. B. Lipika, Multivariate Extreme Value Theory with an Application to Climate Data in the Western Cape Province, Department of statistical sciences, University of Cape Town, 2018.

27. M. R. Makhwiting, M. Lesaoana, and C. Sigauke, Modelling volatility and financial market risk of shares on the Johannesburg stock exchange, African Journal of Business Management, vol. 6, pp. 8065-8070, 2012.

28. A. J. McNeil, and R. Frey, Estimation of Tail Related Risk Measure for Heteroscedastic Financial Time Series: An Extreme Value Approach, J. Empir. Financ., vol. 7, pp. 271-300, 2000.

29. A. Nassif, C. A. Feijo, and E. Araújo, Structural change, catching up and falling behind in the BRICS: A comparative analysis based on trade patterns and Thirlwall's law, PSL Quarterly Review, vol. 69, pp. 373-421, 2016.

30. E. B. Ole, T. Mikosch, and S. I. Resnick, Lévy Processes: Theory and Applications, Birkhäuser, 2013.

31. X. Y. Peng, The downward trend of China's foreign exchange reserves has been formed, in Caixin, from http://opinion.caixin.com/2015-10- 09/100861118.html, 2015.

32. M. Pourahmadi, Construction of skew-normal random variables: Are they linear combination of normals and half-normals, J. Stat. Theory Appl., vol. 3, pp. 314-328, 2007.

33. A. A. Romero, and K. M. Kasibhatla, Volatility dynamics and volatility forecasts of equity returns in BRIC Countries, Journal of business \& economic studies, vol. 19, 2013.

34. A. Salisu, and R. Gupta, Oil shocks and stock market volatility of the BRICS: A GARCH-MIDAS approach, Global Finance Journal, 2020.

35. C. Sigauke, D. Maposa, E. Mudimu, and P. Nyamugure, Volatility modeling using \{ARIMA-GARCH\} models in a hyperinflationary economic environment: The \{Zimbabwean $\}$ experience, SIAM In Peer-reviewed Proceedings of the Annual Conference of the South African Statistical Association, 2010. 
36. B. W. Silverman, Density Estimation for Statistics and Data Analysis, Chapman and Hall, London, 1986.

37. R. L Smith, Statistics of extremes, with applications in environment, insurance, and finance, Monographs on Statistics and Applied Probability, pp. 54-60, 2003.

38. H. Tian, The BRICS and the G20, China \& World Economy, vol. 24, pp. 111-126, 2016.

39. D. Wilson, and R. Puroshothaman, Dreaming with BRICs: The Path to 2050, Global Economic Paper, no. 99, Goldman Sachs, New York, 2003

40. J. Zhang, D. Zhang, J. Wang, and Y. Zhang, Volatility spill-overs between equity and bond markets: Evidence from G7 and BRICS, Romanian Journal of Economic Forecasting, vol. 16, pp. 205-217, 2013. 